San Jose State University

SJSU ScholarWorks

Master's Theses

Master's Theses and Graduate Research

1995

\title{
Comparison of RPE and heart rates of females on a bench step and a treadmill
}

Barbara J. Love

San Jose State University

Follow this and additional works at: https://scholarworks.sjsu.edu/etd_theses

\section{Recommended Citation}

Love, Barbara J., "Comparison of RPE and heart rates of females on a bench step and a treadmill" (1995). Master's Theses. 1009.

DOI: https://doi.org/10.31979/etd.5fpw-p4ff

https://scholarworks.sjsu.edu/etd_theses/1009

This Thesis is brought to you for free and open access by the Master's Theses and Graduate Research at SJSU ScholarWorks. It has been accepted for inclusion in Master's Theses by an authorized administrator of SJSU ScholarWorks. For more information, please contact scholarworks@sjsu.edu. 


\section{INFORMATION TO USERS}

This manuscript has been reproduced from the microfilm master. UMI films the text directly from the original or copy submitted. Thus, some thesis and dissertation copies are in typewriter face, while others may be from any type of computer printer.

The quality of this reproduction is dependent upon the quality of the copy submitted. Broken or indistinct print, colored or poor quality illustrations and photographs, print bleedthrough, substandard margins, and improper alignment can adversely affect reproduction.

In the unlikely event that the author did not send UMI a complete manuscript and there are missing pages, these will be noted. Also, if unauthorized copyright material had to be removed, a note will indicate the deletion.

Oversize materials (e.g., maps, drawings, charts) are reproduced by sectioning the original, beginning at the upper left-hand corner and contiming from left to right in equal sections with small overlaps. Each original is also photographed in one exposure and is included in reduced form at the back of the book.

Photographs included in the original manuscript have been reproduced xerographically in this copy. Higher quality $6^{\prime \prime} \times 9^{n}$ black and white photographic prints are available for any photographs or illustrations appearing in this copy for an additional charge. Contact UMI directly to order.

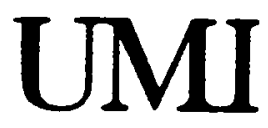

A Bell \& Howell information Company 300 North Zeeb Road. Ann Afbor. MI 48106-1346 USA $313: 761-4700 \quad 800: 521-0600$ 


\title{
COMPARISON OF RPE AND HEART RATES OF FEMALES ON A BENCH STEP AND A TREADMILL
}

\author{
A Thesis \\ Presented to \\ The Faculty of the Department of Human Performance \\ San Jose State University
}

In Partial Fulfillment

of the Requirements for the Degree

Master of Arts

By

Barbara J. Love

May 1995 
UMI Number: 1374600

UMI Microform 1374600

Copyright 1995, by UMI Company. All rights reserved.

This microform edition is protected against unauthorized copying under Title 17, United states Code.

\section{UMI}

300 North zeeb Road

Ann Arbor, MI 48103 
(C) 1995

Barbara J. Love

ALL RIGHTS RESERVED 
APPROVED FOR THE DEPARTMENT OF HUMAN PERFORMANCE

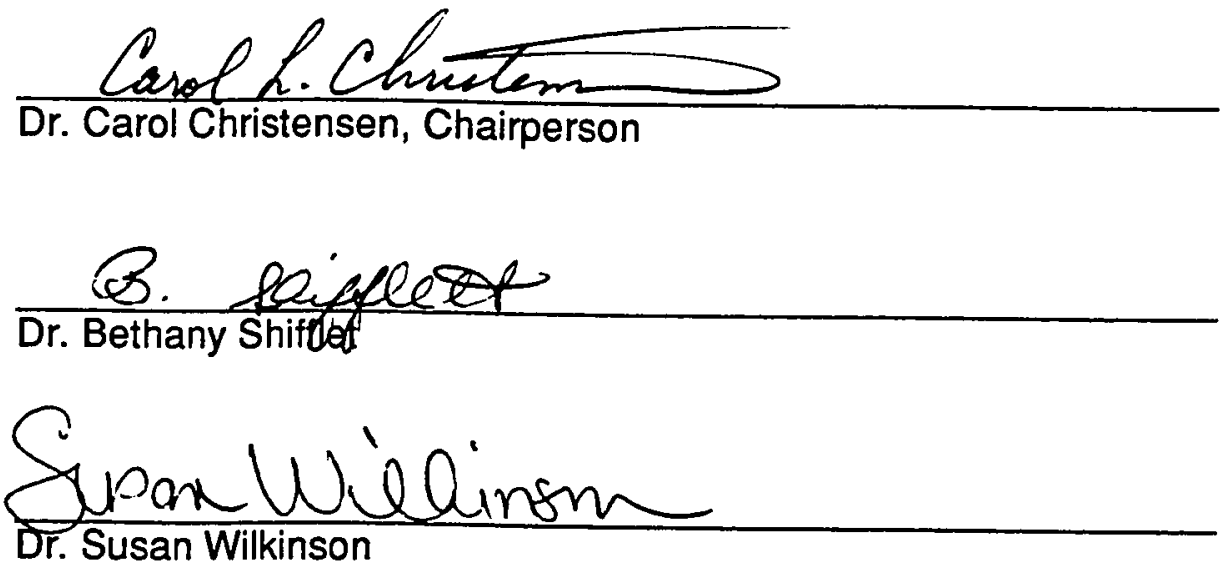

APPROVED FOR THE UNIVERSITY

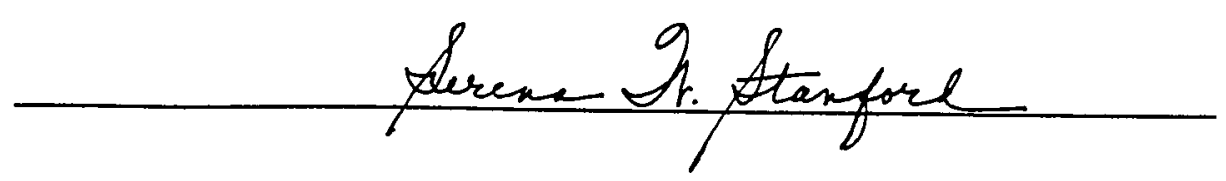




\section{ABSTRACT \\ COMPARISON OF RPE AND HEART RATES OF FEMALES ON A BENCH STEP AND A TREADMILL \\ by Barbara J. Love}

This study investigated differences in heart rates (HR) and ratings of perceived exertion (RPE) levels of 39 females (mean age $=28.8 \mathrm{yrs}$ ) during submaximal exercise on a bench step and a treadmill. Each subject completed a six minute step test and maximal treadmill test. Data were analyzed using a dependent $\mathrm{t}$-test revealing significant differences in heart rates at a target rating of perceived exertion (TRPE) level. These findings also demonstrated that a majority of the subjects had heart rates on the bench step indicating greater physiological stress than their perceived exertion values indicated. 


\section{ACKNOWLEDGMENTS}

First I would like to thank my committee members for all their efforts, patience, and support, specifically my advisor, Dr. Carol Christensen. If not for you this project would not exist. I am grateful that you allowed me to shape it, work with it, and at last, complete it. Special thanks to Dr. Bethany Shifflet for your keen input and statistical wizardry. Your knowledge and enthusiasm for your craft is truly inspirational. Thank you, Dr. Susan Wilkinson for your helpful comments and suggestions.

I would like to thank my sister Kate for bringing me to California in the first place. You always believed in me and convinced me that I could get through graduate school. I guess you were right! A very special thanks to my many wonderful friends and family who supported me throughout this project and offered their time and words of encouragement. A heartfelt thanks goes out to all of my volunteer and pilot subjects and testing assistants who gave so generously of their time and of themselves. You did a great job!

Finally to my raison d'être, my daughter, Erin. It is to you, that I dedicate this thesis. I hope that some day, you too, will seek out higher education. 


\section{TABLE OF CONTENTS}

Page

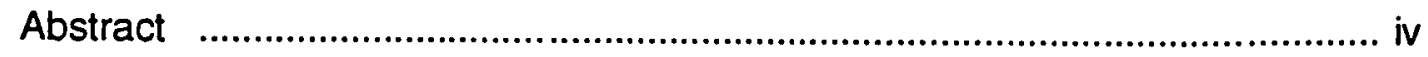

Acknowledgments ................................................................................... v

Table of Contents

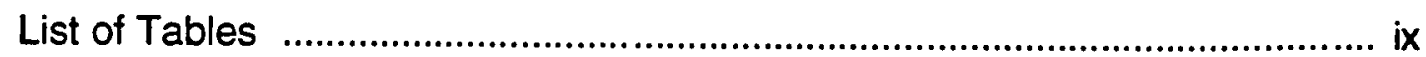

\section{Chapter}

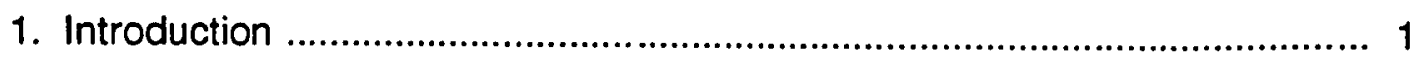

Statement of the Purpose ................................................................... 2

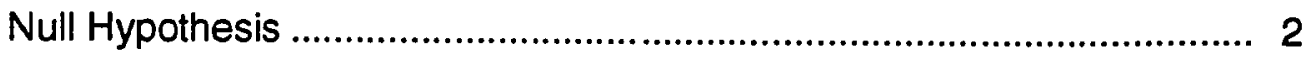

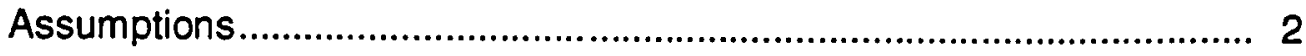

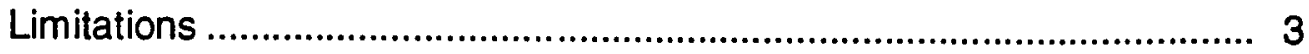

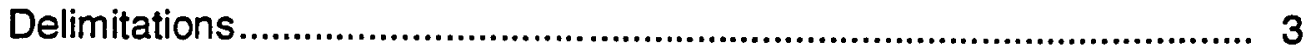

Definitions of Terms ................................................................................. 4

2. Review of Literature

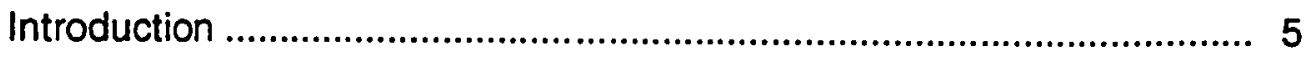

Rating of Perceived Exertion ................................................................ 5

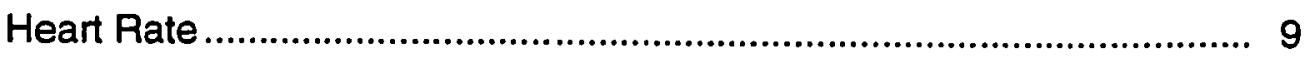

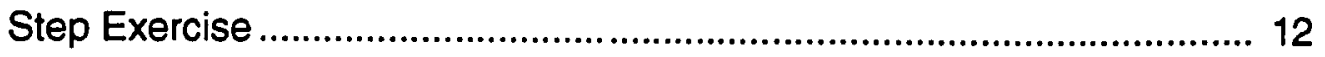

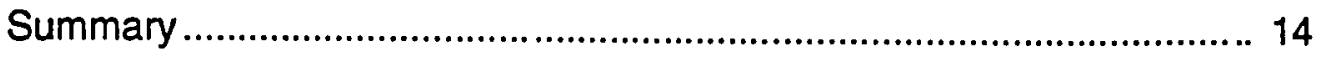

3. Methods

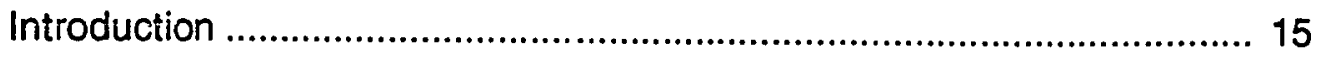

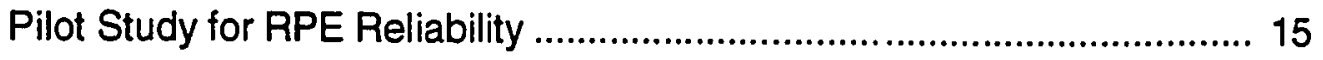

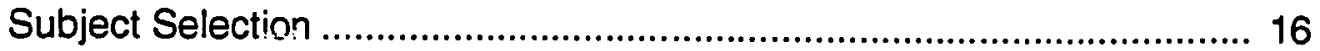


Measurements

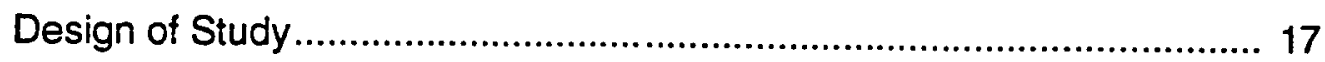

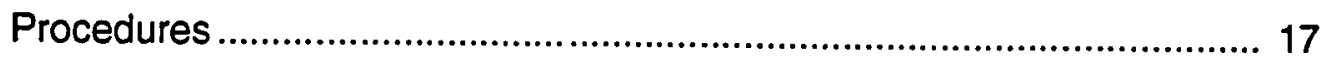

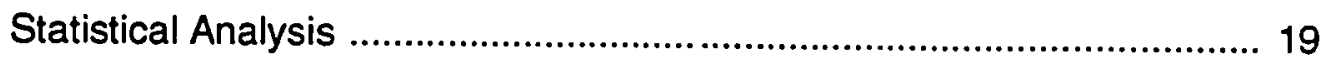

4. Results and Discussion

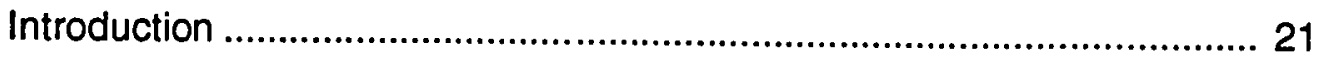

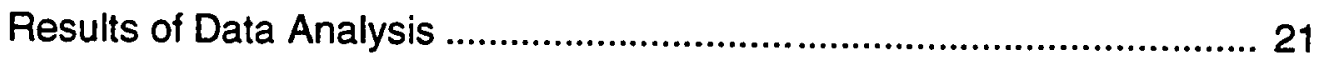

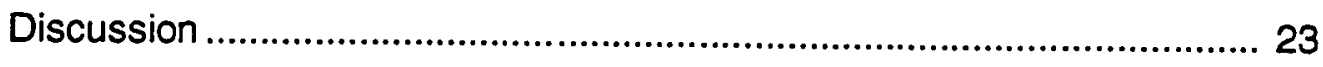

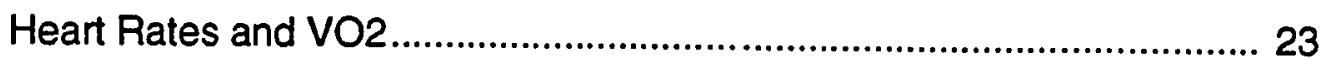

Step Experience, prior RPE use, and fitness level................................ 30

Psychological Phenomenon .................................................................... 34

RPE

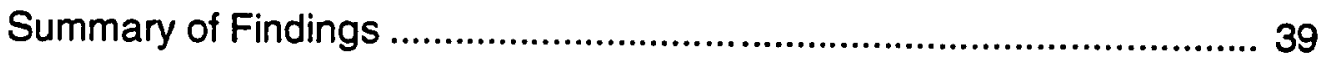

5. Summary, Conclusions, and Recommendations ........................................ 40

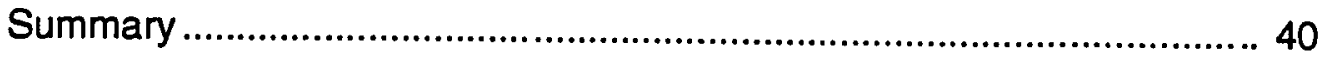

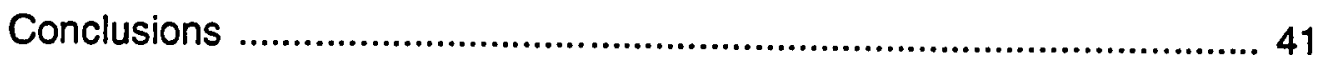

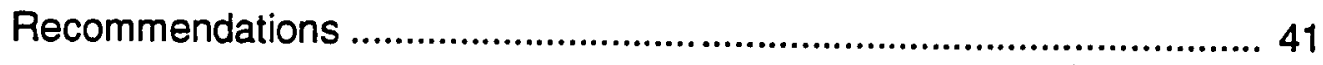

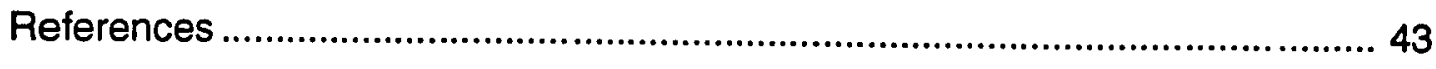

Appendices

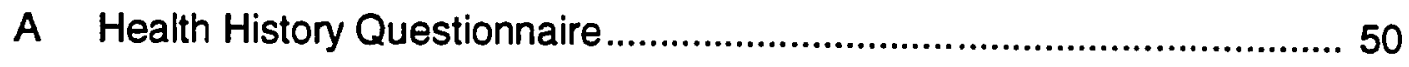

B Informed Consent Form ................................................................. 53

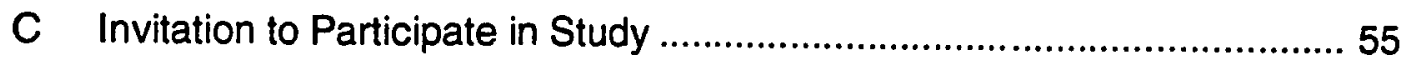

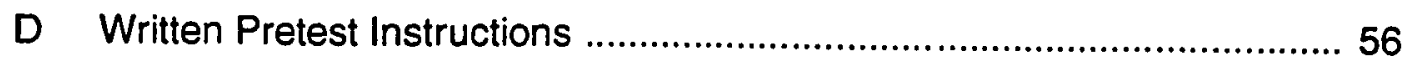


E Borg's Rating of Perceived Exertion Scale ......................................... 57

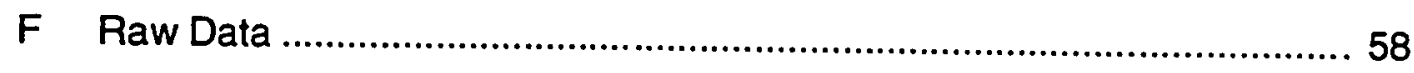

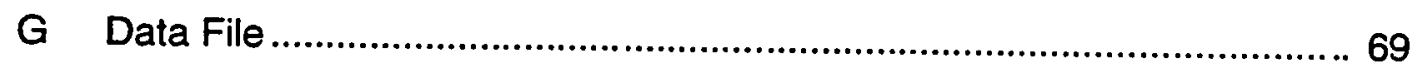

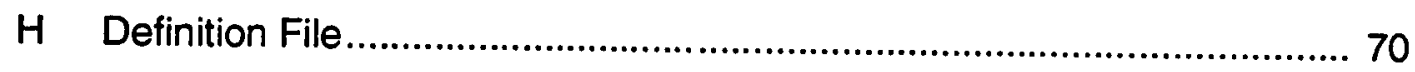

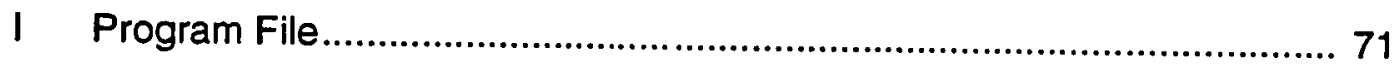


List of Tables

Table

1. Descriptive Characteristics for All Subjects ....................................... 22

2. Subject's Prior RPE Use and Step Experience ................................... 22

3. Mean Heart Rates and Dependent $₫$ test Results .................................... 24

4. Mean Heart Rates (HR) for All Subjects on Step and Treadmill at TRPE... 25

5. Ventilation, Energy Costs, and Heart Rates for Randomly Selected Subjects at TRPE 26

6. Selected Minute by Minute Heart Rate Data for Step (ST) and Treadmill (TM ) Exercise

7. Number of Subjects with Higher Step \& Treadmill Heart Rates Based on Step Experience 32

8. Number of Subjects with Higher Step \& Treadmill Heart Rates Based on Prior RPE Use 32

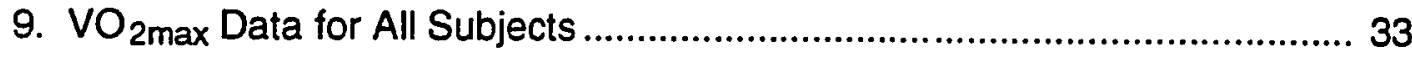

10. RPE Correction Factor for Subjects with Heart Rates (HR) within Adjusted Heart Rate Range at TRPE 36

11. RPE Correction Factor for Subjects Whose Heart Rates (HR) were Outside the Adjusted Heart Rate Range at TRPE 


\section{CHAPTER ONE}

\section{INTRODUCTION}

Step aerobics became popular during the 1990's. Names for this challenging workout include step or bench training, step aerobics, bench aerobics, the Step, and "a poor man's stair climber" (Harste, 1990). No matter what it is called, there is no denying its popularity. Step classes have been filled to capacity, usually with a predominantly female population. What is the appeal of stepping up and down on a 4 inch to 12 inch bench? Participants state that the camaraderie of classmates, high intensity music, and an enthusiastic instructor makes bench aerobics very motivating and lots of fun (Aldridge, 1990).

Dr. Lorna Francis, an instructor of physical education at San Diego State University who has studied bench aerobics, noted that stepping is a fairly mild activity compared with running and "the impact may even be slightly lower than walking" (Harste,1990, p. 26). Impact is an important aspect for exercisers who complain of aches, pains, and injuries that can occur due to repeated pounding of the feet on the ground. Dr. Francis discovered that the intensity of bench aerobics was virtually the same as running at 7 miles per hour (Francis, 1990). However, Dr. Francis does issue a warning to those new to bench aerobics. "It's important for novices to begin the program with their physician's approval and on a low (4 inch) platform for a short time" (Harste, p. 26).

A standard measurement tool to monitor exercise intensity is a 15-point exertion scale that corresponds to various heart rates developed by Gunnar Borg in 1970 (Monahan, 1988). It is a "valid" (Dunbar et al., 1992) and reliable (Eston $\&$ Williams, 1988) perception scale that is easy to learn and simple to use. 
"Subjects are taught to relate the way they feel at different levels of exercise intensity to the physiologic changes induced by exercise" (Monahan, p. 174). In other words, exercisers who use rating of perceived exertion (RPE) are able to monitor exercise intensity in the context of how they feel.

The American College of Sports Medicine [ACSM] (1990) recommends the intensity level of training be $60-90 \%$ of maximum heart rate $\left(\mathrm{HR}_{\max }\right)$, or 50 $85 \%$ of maximum oxygen uptake $\left(\mathrm{VO}_{2 \max }\right)$. When combining methods of using percentage of estimated $H R_{\max }$ and RPE, exercisers should be able to monitor their exercise intensity accurately. Or can they? Thomas and Long (1993) studied heart rate and rating of perceived exertion responses to aerobic bench training. Their results indicated that RPE did not correlate well with heart rate in female subjects during bench aerobics. Further studies are necessary to determine if RPE should be used to monitor exercise responses in female bench step trainers.

\section{Statement of the Purpose}

The purpose of this study was to determine if heart rates reflect the same rating of perceived exertion level (RPE) at target RPE (TRPE) in females while exercising on a bench step and on a treadmill.

\section{Null Hypothesis}

There will be no significant differences in heart rates for subjects on a bench step and on a treadmill at target RPE.

\section{Assumptions}

The following assumptions were made for the purpose of this study.

1. Subjects responded accurately and honestly to the health history and activity questionnaire. 
2. Subjects were physically able to complete the step and treadmill exercise sessions.

3. Subjects refrained from any unfamiliar exercise on, and 24 hours prior to, testing days.

4. The exertion levels and heart rates reached were representative and commonly experienced when performing the exercise tests.

5. Subjects were motivated and willing to cooperate.

6. Subjects understood, interpreted, and performed all tests to the best of their abilities.

7. Subjects were in good health 24 hours prior to, and on, testing days.

8. Subjects were able to subjectively evaluate their work intensity using the Borg scale and the scale was used accurately.

\section{Limitations}

The limitations of this study were as follows:

1. Individual differences in the level of training may have affected HR and RPE responses.

2. Thirty-three subjects had prior bench step training.

3. Subject's personal habits such as diet, exercise, and rest prior to test administration may have affected HR and RPE responses.

\section{Delimitations}

The delimitations of this study included the following:

1. The subjects were apparently healthy females from 21 to 41 years of age.

2. Subjects were recruited from San Jose State University and local health clubs. 


\section{Definitions of Terms}

Basic Step Routine

Stepping up and down repeatedly on a bench step.

Heart Rate Reserve (HRR)

The difference between the resting heart rate and the maximal heart rate (Fox, Bowers \& Foss, 1989).

Intensity

The physiological stress on the body during exercise that reflects the rate of energy expended.

Maximal Heart Rate $\left(\mathrm{HR}_{\max }\right)$

The maximum heart rate a person can achieve during high intensity exercise.

Predicted maximal heart rate is calculated as 220 - age (ACSM, 1991).

Rating of Perceived Exertion (RPE) Scale

A measurement tool to subjectively monitor exercise intensity corresponding to various heart rates (Monahan, 1988).

Steady State

The time period during which oxygen consumption remains at a relatively constant level (Fox, Bowers, \& Foss, 1989).

\section{Step Exercise}

Aerobic exercise using a raised platform or step. 


\section{CHAPTER TWO}

\section{REVIEW OF LITERATURE}

\section{Introduction}

This section includes a review of these major topics: (a) rating of perceived exertion levels as a method to gage exercise intensity, (b) heart rate, and (c) step exercise.

\section{Rating of Perceived Exertion}

The American College of Sports Medicine (ACSM, 1990) advocates the use of ratings of perceived exertion (RPE) as a useful tool to monitor exercise intensity once the relationship between heart rate and RPE is known. This relationship has been the subject of numerous studies (Eston, Davies, \& Williams, 1987; Glass, Whaley \& Wegner, 1991; Noble, 1982; Robertson, 1982 ) since the inception of psychophysical scaling of perceived exertion in the late 1950s (Borg \& Ottoson, 1986). Gunnar Borg admits that the idea of using subjective classifications (light, moderate and very heavy) to determine physical work has been around since the late 1920s (Borg \& Ottoson). The difference from the past and present is "the possibility of measuring subjective intensities, relating these measurements to the corresponding physical intensities, and describing the functional relation in a way that parallel corresponding physiological relations" (Borg \& Ottoson, p. 8).

Borg authored many studies using perceptual responses to monitor work intensity and there are several versions of his scale. However, it is the 15 point scale developed in 1970 that is widely used today (Birk \& Birk, 1987). 
Rating of perceived exertion is also used as a method to prescribe exercise intensity. The ACSM (1991) states, "that the individual participant's RPE response to graded exercise may be employed in specifying the RPE level for conditioning" (p. 102). Glass, Knowlton, and Becque (1992) examined the accuracy of using RPE responses obtained during a graded exercise test (GXT) as a means to prescribe exercise intensity. Fifteen male subjects exercised for ten minutes on a treadmill (subjects selected the speed) at the prescribed RPE obtained from a previous GXT. The subjects were within four beats per minute of the target heart rate substantiating the use of RPE to establish an exercise training intensity.

In similar studies, Thompson and Foster (1990) and Dishman, Patton, Smith, Weinberg, and Jackson (1987) discovered that RPE alone did not predict exercise intensity well; however, when used in conjunction with heart rate, RPE proved to be an accurate method to prescribe and monitor exercise intensity. The close relationship that RPE and heart rate enjoy is, according to Borg (1982), "not intended to be taken too literally because the meaning of a certain heart rate value as an indicator of strain depends upon age, type of exercise, environment, anxiety and other factors" (p. 379).

Results of a study by Whaley, Woodall, Kaminsky, and Emmett (1992) contradicted the findings of previous studies. They investigated RPE responses to a field test (paced jogging at 70 to 80 percent $H_{R_{\max }}$ reserve (THR)) and two treadmill tests using Bruce and Balke protocols. The subjects were older, untrained men ( $n=19)$ and women $(n=19)$. The RPE responses at THR during the field test were significantly lower than the RPE responses at THR during the 
two GXTs. The significantly lower RPE responses could result in overexertion in untrained exercisers.

In a similar study conducted by Ceci and Hassmen (1991), RPE was tested on an outdoor track and during treadmill running. It was suggested that environmental factors such as wind resistance and visual stimuli would confound responses. Trained males $(n=11)$ participated and the results showed heart rates were significantly higher at various RPE levels in the field setting. These results are consistent with the above study. The authors suggest that a distinction be made whether exercise prescription will be based on clinical or more natural settings. A possible solution could be to subtract approximately two RPE units from the treadmill responses and apply it to exercise taking place in a field situation. The authors indicated the data collected supported their suggestion. For individuals who are untrained and/or suffer from disease the authors recommended that an RPE of 13 or below be used in a field situation whereas an RPE of 15 be prescribed for treadmill/clinical use.

Dunbar et al. (1992) discovered RPE to be a physiologically "valid" method to regulate exercise intensity during cycle ergometer tests at 50 and 70 percent $\mathrm{VO}_{2 \max }$, but not "valid" during a 70 percent $\mathrm{VO}_{2 \max }$ treadmill test. Seventeen males, ages 17-35 years performed one familiarization trial, two estimation trials and four production trials. The familiarization trial was used to aquaint the subject with the Borg scale. The subject read a brief set of instructions and was given a verbal explanation on its use. Subjects also exercised for 10 minutes on the treadmill and cycle ergometer to practice adjusting speed and resistance. One estimation trial was administered on a treadmill to determine $\mathrm{VO}_{2 \max }$ while a cycle ergometer was used for the other 
trial. RPEs were estimated at each minute of exercise for both trials. During the production trials the subject was given the RPE that corresponded with 50 and 70 percent of their $\mathrm{VO}_{2 \max }$. Subjects were instructed to manipulate the treadmill speed or pedal resistance until they reached the level of exertion previously attained during the estimation trials. The results of the production trials showed that when exercise intensity was regulated by target RPE acheived on the cycle ergometer, the accuracy was excellent both intra- and intermodally. However, when RPE data was used from the treadmill estimation trial, it was not valid at 70 percent $\mathrm{VO}_{2 \max }$. The authors attributed this to relatively slow speeds and large inclines included in the treadmill protocol.

Some researchers have supported the use of RPE alone (Birk \& Birk, 1987; Eston, et al., 1987; Eston \& Williams, 1988) to monitor exercise intensity; others contend RPE should be used in conjunction with heart rate (Dishman et al., 1987; Thompson \& Foster, 1992). Still others find RPE more advantageous than heart rate as an exercise monitoring tool (Robertson et al., 1990) due to the difficulty often experienced by many participants when trying to obtain heart rates during exercise.

In a study conducted by Nethery (1992), 13 untrained males completed four 15 minute cycling sessions (control, visual and auditory deprivation, video, and music conditions). RPE responses were significantly lower when exercising to music as compared to the other conditions. This observation is interesting considering that most aerobic dance and step exercise is performed to a pulsating, rhythmic beat. Research such as this further substantiates the use of caution when using RPE to monitor exercise intensity during step exercise. 
Although research is mixed on how best to use RPE, alone or in conjunction with monitoring heart rates, results consistently show that it is a useful tool to monitor exertion levels when exercising. Research must now focus on ways to establish the optimal conditions under which RPE would elicit the most accurate measure of exercise in!ensity.

\section{Heart Rate}

The American College of Sports Medicine (ACSM) position paper published in 1990 stated that intensity of exercise should be maintained at a level between 60 and 90 percent of $\mathrm{HR}_{\max }$. Heart rate has been used extensively to monitor exercise intensity (Parker, Hurley, Hanlon, \& Vaccaro, 1989) and as a tool for exercise prescription (Karvonen \& Vuorimaa, 1988). Heart rate has been the subject of numerous studies (Berry, Cline, Berry, \& Davis, 1992; Hornsby, Dixon, Anderson, and East, 1991; Matheny \& Swain, 1991; Parker et al., 1989; Reeves \& Darby, 1991; Ryshon, Kemp, \& Johnson, 1991; Stanforth, Hamman, \& Senechal, 1988; and Thomas \& Londeree, 1989) relating to oxygen consumption, exercise intensity, and its variation with differing exercise modalities.

A popular method to estimate maximal heart rate is to use the agepredicted formula (Fox et al., 1989). One study investigated the validity of the "220-age" formula to predict maximal heart rate (Ricard, Leger, \& Massicotte, 1990). Results indicated that this formula systematically overestimates $\mathrm{HR}_{\max }$ which can affect target heart rate and $\mathrm{VO}_{2 \max }$ prediction for training. Despite these results, the "220-age" formula continues to be used as a tool to measure $\mathrm{HR}_{\max }$ (Bryant \& Peterson, 1992). Karvonen and Vuorimaa (1988) believe that a laboratory setting is best for obtaining an appropriate target heart rate for training. 
However, lab testing is time consuming and costly and is neither feasible nor available for most of the general population.

Heart rate and maximal oxygen uptake $\left(\mathrm{VO}_{2 \max }\right)$ usually have a linear relationship at submaximal levels (between 115 and 150 beats per minute) (Bryant \& Peterson, 1992). Generally, the higher the heart rate, the greater the oxygen demand. Maximal oxygen uptake is the standard indicator of a person's cardiovascular fitness. " $\mathrm{VO}_{2 \max }$ provides a quantitative statement of an individual's capacity for aerobic energy transfer" (McArdle, Katch, \& Katch, 1991, p. 131). To predict $V_{2 \max }$ based on heart rate, Bryant and Peterson (1992) suggested that the following assumptions must be made: 1) a linear relationship exists between heart rate, oxygen uptake $\left(\mathrm{VO}_{2}\right)$ and workload; 2) a steady-state heart rate is obtained for each exercise workload; 3) the maximal heart rate for a given age is uniform; 4) the mechanical efficiency of exercise at a given work rate for a specific type of exercise is the same for everyone; and 5) day-to-day variations in submaximal heart rate do not exist. The assumptions just stated are only approximately correct as "maximal heart can vary greatly among individuals of the same age, oxygen uptake at any given work rate can vary by approximately 15 percent, and submaximal heart rates will vary day to day with a given individual" (p. 39).

Based on the assumption that heart rate increases linearly with increases in $\mathrm{VO}_{2}$, Parker et al. (1989) studied 14 untrained females during an aerobic dance session. Heart rate and $\mathrm{VO}_{2}$ were measured using an ECG monitor and gas analysis equipment. The subjects performed a 20 minute aerobic dance session and within one week performed a treadmill jogging test at the same $\mathrm{VO}_{2}$. The heart rate responses and $\mathrm{VO}_{2}$ for the aerobic exercise session were 
compared to those of the treadmill test. The $\mathrm{VO}_{2}$ values based on a percentage of $\mathrm{VO}_{2 \max }$ were nearly identical (aerobic dance $=62.3 \%$, treadmill $=62.7 \%$ ). However, the heart rates for the aerobic dance session were 10 percent higher than treadmill jogging (180 bpm versus $163 \mathrm{bpm}$ ). The authors concluded that target heart rate (age predicted) failed to accurately monitor intensity during aerobic dance.

Berry et al. (1992) conducted a follow up study to replicate Parker's results. Their results contradicted the contention that aerobic dance exercise results in a disproportionately higher heart rate for a given $\mathrm{VO}_{2}$. Extensive use of the arms was the possible explanation for this disparity. Nine healthy females exercised at 50 percent of their $\mathrm{VO}_{2 \max }$ during two forms of aerobic dance and treadmill running. During one of the 20 minute aerobic dance trials, the subject used the arms extensively overhead. During the other trial, the arms were kept below the shoulders. Both routines were high impact consisting of hops, jumps, skips, kicks, and jogging in place. The treadmill exercise was used to determine $\mathrm{VO}_{2 \max }$. No significant differences in HRs were noted during each of the three submaximal exercise tests. These results suggest that a similar relationship exists between heart rate and $\mathrm{VO}_{2}$ during aerobic dance exercise and treadmill running.

In their study, Reeves and Darby (1991) designed a maximal graded dance exercise test (DET) to elicit more accurate $\mathrm{VO}_{2 \max }$ test results. Based on the concept of specificity of training, the investigators wanted to determine if physiological responses were specific to aerobic dance. A comparison was made to how $\mathrm{HR}_{\max }$ and $\mathrm{VO}_{2 \max }$ related to a treadmill run test (TRT) and a DET that was choreographed to elicit physiological responses similar to running. Ten 
college-age females completed both exercise tests. $\mathrm{VO}_{2}$ values for the TRT

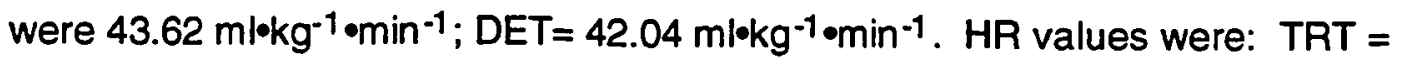
$195.7 \mathrm{bpm} ; \mathrm{DET}=196.6 \mathrm{bpm}$. There were no significant differences in the physiological responses. The results of the study suggested that $\mathrm{HRs}$ and $\mathrm{VO}_{2}$ values were similar for both tests and attributed this to the training of similar muscle groups and the use of a large muscle mass in both exercise modalities.

\section{Step Exercise}

Step exercise has taken on a new look since its clinical use in the earlier part of the twentieth century (Holland, Hoffmann, Vincent, Mayers, \& Caston, 1990). Step treadmills were used by prisoners for exercise and were popularized by the development of the Master's step test to determine aerobic fitness (Holland et al.). Some research indicated that step tests can accurately predict oxygen consumption at submaximal levels (Ahlquist et al., 1991; Samuels et al., 1991). However, contradictory results have been obtained by other investigators as discussed below.

A study conducted by Thomas, Weller, and Cox (1993) used a submaximal step test and included the variables that could contribute to variation in oxygen demands. The subject's physical characteristics (age, gender, body composition, aerobic fitness, and leg length) were used in their calculations to enhance the accuracy of $\mathrm{VO}_{2 \max }$ prediction. The modified Canadian Aerobic Fitness Test (CAFT) was used to examine oxygen consumption during four different submaximal step tests. The sample included 121 subjects, including male $(n=55)$ and female $(n=66)$ volunteers. Each subject stepped on a double bench step for three minutes at progressively higher cadences until they reached the highest level of the CAFT or a target heart rate of 85 percent of age-predicted 
$H R_{\max }$. The results showed a 10.4 percent average variation in oxygen uptake at a given step cadence. "Variation in the oxygen demand of stepping between individuals may be an important source of error in the prediction of maximum oxygen uptake" (Thomas et al., 1993, p. 141). This variation impacts the accuracy to which aerobic fitness can be predicted using an individual's characteristics. The results indicated that aerobic fitness, age, leg length, and body composition can contribute to approximately one third of the variability in oxygen demand among subjects.

Recent research has identified step exercise as a means of providing cardiorespiratory demands necessary for enhancing aerobic fitness. Velasquez and Wilmore (1992) investigated the results of a 12-week bench training program which required participants to attend 30 minute exercise sessions, three times per week exercising at an intensity of 70 to 85 percent of $\mathrm{HR}_{\max }$ reserve. Using an ANOVA with repeated measures, results showed significant increases in $\mathrm{VO}_{2 \max }$ and maximum ventilation and significantly decreased resting heart rate and submaximal heart rate. There were no significant differences in body composition following the training program.

Thomas and Long (1993) studied the relationship of heart rate and RPE during aerobic bench exercise. Twenty females exercised for 28 minutes on a six inch step, with a 120 steps per minute rate for the first 17 minutes and a 140 steps per minute rate for the remaining 11 minutes. Heart rate and RPE were monitored and recorded starting with the fifth minute and every three minutes thereafter. Heart rate and RPE correlated well over the entire duration of the step test $(r=.94$ at $p<.05)$. However, when the correlation coefficient was calculated for each interval, HR and RPE did not correlate significantly. 
Given that step exercise classes include many participants, exercise leaders should use caution when setting group RPE or HR levels. Individual responses will be different and each participant should monitor their own progress throurhout the exercise session.

\section{Summary}

Step exercise may be a popular way to achieve fitness on the aerobics scene for many people. It has proven to provide cardiorespiratory benefits (Olson, Williford, Blessing, \& Greathouse, 1991) to those who are willing to repeatedly step up and down on a bench. Research in this area is limited but is gaining in prevalence as this mode of exercise maintains popularity.

Based on the results of Thomas and Long (1993), additional research should be conducted to determine if rating of perceived exertion and heart rate responses can safely and accurately monitor intensity in this popular form of aerobic exercise. 


\section{CHAPTER THREE}

\section{METHODS}

\section{Introduction}

This investigation focused on the physiologic responses, specifically, heart rates and ratings of perceived exertion, of females while exercising on a bench step and a treadmill. This chapter contains descriptions of the pilot study, subjects, measurements, design of study, procedures, instrumentation, and statistical analysis.

\section{Pilot Study for RPE Reliability}

Twenty-one volunteers from three separate step classes $(n=7, n=4$, and $n=10)$ participated in a test, retest study to determine RPE reliability. The principal investigator explained the test protocol and read instructions for the use of Borg's ratings of perceived exertion scale (ACSM, 1991). The test consisted of a 5-minute submaximal step test on a 6-inch step at a rate of 120 steps per minute. A metronome was used to establish and maintain cadence. At the conclusion of the test, volunteers were instructed to write down their names, the date, whether or not they had used the RPE scale previously, and the level of perceived exertion they chose from the chart provided. The principal investigator provided the volunteers with $3 \times 5$ index cards and pencils. Subjects were then asked to return on a specified date to repeat the test $(n=7$ returned one week later, $n=4$ and $n=10$ returned two days later). The procedures stated previously were followed. The subjects repeated the 5-minute step test and were instructed 
to record their RPE on a new $3 \times 5$ index card. The two measures of RPE were used to assess reliability using coefficient alpha.

\section{Subject Selection}

Forty-two female subjects were recruited from step classes at San Jose State University and local health clubs located throughout the Bay area. Testing procedures were explained by the author verbally and in writing. Subjects were advised of the possible risks involved as a result of participation in this study and of their rights as subjects. All subjects read and signed an informed consent form (Appendix B) approved by the San Jose State University Institutional Review Board: Human Subjects. The health history questionnaire and consent form were completed and reviewed prior to testing.

\section{Measurements}

Each subject was measured for height in centimeters using a stadiometer and weight in kilograms using a platform balance scale. Skinfold thicknesses were measured by Lange calipers at the triceps, suprailium, and thigh (ACSM, 1991). Body fat percentage was estimated using the generalized equations of Jackson, Pollock, and Ward (1980). Body fat percentages were used only for descriptive purposes for this study and to provide subjects with personal information. Heart rate was measured with a Nihon-Kohden Cardiofax $V$ electrocardiograph, Model ECG 8330-A using the single ECG CM5 lead configuration. Blood pressure was measured using a standard mercury sphygmomanometer and stethoscope. Finally, a Medgraphics CPX-D metabolic cart was used to measure gas exchange variables to determine $\mathrm{VO}_{2 \max }$. 


\section{Design of Study}

Written notices (Appendix $\mathrm{C}$ ) soliciting volunteers for this study were placed on bulletin boards, given to instructors to announce in step classes at San Jose State University and at local area health clubs. Forty-two females meeting stated criteria were chosen to participate. Upon selection, subjects received (a) a Health History Questionnaire (Appendix A), (b) an informed consent form (Appendix B), and (c) written pretest instructions (Appendix D). Subjects were asked to wear comfortable exercise clothes and rubber-soled exercise shoes. Each subject was asked to bring their own towel and water bottle. Subjects were asked to refrain from eating, smoking, or drinking caffeinated beverages for at least four hours prior to test administration, and from any unusual exercise at least twenty-four hours prior to testing, and from any exercise during the two hours prior to testing.

\section{Procedures}

Subjects were scheduled to report to the San Jose State University Human Performance Exercise Physiology and Biomechanics Laboratory for testing. Each subject was tested separately and completed all tests during one session. Each subject was welcomed and given an explanation of what events were to take place during the test administration. A completed health history questionnaire and informed consent form was collected if not received prior to testing. Measurements of height, weight, and skinfold thicknesses were taken for each subject. Electrodes were then placed on subjects using the single ECG CM5 lead configuration (ACSM,1991). Subject's pre-exercise blood pressure and heart rate data were measured followed by exercise data taken from the step and treadmill exercise portion of testing. 
"The Step ${ }^{T M " ~ w a s ~ u s e d ~ f o r ~ t h e ~ b e n c h ~ s t e p ~ p o r t i o n ~ o f ~ t h i s ~ s t u d y . ~ S t e p s ~ a r e ~}$ owned by San Jose State University's Human Performance Department and are licensed by Reebok International, Inc.

A demonstration and explanation of the bench step and basic step routine was given. Subjects were given written instructions to read for an explanation of the use of the Borg scale (Appendix E). Subjects were fitted with a mouthpiece and nose clip for gas analysis. After 1 minute of resting data were collected, each subject performed a basic stepping routine on a 6 -inch step at 120 steps per minute for 6 minutes. A metronome set at $120 \mathrm{bpm}$ was used to establish and maintain cadence. Ratings of perceived exertion were taken during the final 10 seconds of minutes 4, 5, and 6 . Target RPE (TRPE) was determined by two RPEs of the same value or RPE at minute 5. Heart rate was continuously monitored and recorded during the last 10 seconds of each minute. The subject rested for approximately 5 minutes or until heart rate returned to within 20 beats of pre-exercise heart rates.

Instructions were given for the treadmill exercise; a demonstration and a practice walk to become familiar with the treadmill was given if requested by the subject. Subjects began the treadmill test by walking at 3.0 miles per hour at $0 \%$ grade. The pace of $3.0 \mathrm{mph}$ was selected because it requires approximately 120 steps per minute, similar to the cadence of 120 steps per minute on the bench step. Grade was increased $1 \%$ each minute if RPE was within 3 digits of TRPE and $2 \%$ each minute if RPE was greater than 3 digits from TRPE. The minute at which TRPE was reached was noted. The minute after TRPE was reached, a maximal aerobic capacity test commenced with no interruption of exercise. Speed was increased to $3.5 \mathrm{mph}$ for one minute and increased again to $4.0 \mathrm{mph}$; 
no other speed increases occurred. Grade was increased 1 to $3 \%$ each minute depending on stated RPE and nearness of voluntary exhaustion. Exercise continued until the subject reached voluntary exhaustion. Ratings of perceived exertion were taken during the last 10 seconds of each minute of exercise. Heart rate was continuously monitored and recorded during the last 10 seconds of each minute. Maximal oxygen uptake levels were measured and a printout listing minute to minute gas exchange variables was provided by the Medgraphics CPX-D metabolic cart.

At the end of the test, treadmill speed and slope were quickly decreased to $2.5 \mathrm{mph}$ and $0 \%$ grade for a cooldown walk. Subjects were monitored following exercise until heart rate was below 120 beats per minute.

\section{Statistical Analysis}

Heart rates were calculated using data from 39 of the 42 subjects. Three subjects failed to obtain TRPE on the treadmill portion of the exercise testing and they were excluded from the statistical analysis. Means, standard deviations, and ranges were used to describe physiologic characteristics of subjects such as age, height, weight, $\mathrm{VO}_{2 \max }$, and body fat percentage. Frequency distribution tables presented the following variables: prior RPE use, step experience, age, HRs and RPEs at minutes 4, 5, and 6 on the step, HRs and RPEs at each minute during treadmill exercise, TRPE, $\mathrm{HR}_{\max }, \mathrm{VO}_{2 \max }$, and body fat percentage. The independent variable was the type of exercise (bench step or the treadmill) and the dependent variables were heart rates at TRPE of the subjects. A dependent 1 test was used to compare heart rates at TRPE levels. An alpha level of .05 was used to determine statistical significance. Coefficient alpha was used to calculate 
the reliability from the results of the pilot study. The SSPS statistical computer program was used for calculations. 


\title{
CHAPTER FOUR
}

\section{RESULTS AND DISCUSSION}

\author{
Introduction
}

This chapter presents the results of data analysis and discussion for this study. Data from this study were analyzed to determine if the subject's heart rates reflected the same ratings of perceived exertion (RPE) levels at target RPE while exercising on a bench step and a treadmill.

\section{Results of Data Analysis}

A pilot study was conducted to determine the reliability of two RPE levels taken from 21 subjects from three local step classes. The mean RPE for test one was 9.6 and the mean RPE for test two was 9.5. The statistical test coefficient alpha determined the reliability of the two RPE measures to be .78 .

The mean descriptive characteristics for the 39 subjects used in the analysis are summarized in Table 1. The mean age was 28.8 years $(\underline{S D}=4.66$ yrs), mean height was $164.5 \mathrm{~cm},(\underline{S D}=6.09 \mathrm{~cm})$, mean weight was $61.5 \mathrm{~kg}$ ( $\underline{\mathrm{SD}}$ $=14.42 \mathrm{~kg})$ and mean body fat was $21.6 \%(\underline{S D}=4.52 \%)$. The mean $\mathrm{VO}_{2 \max }$ was $44.3 \mathrm{ml}^{\circ} \mathrm{kg}^{-1} \bullet \mathrm{min}^{-1}\left(\underline{\mathrm{SD}}=7.62 \mathrm{ml}^{\circ} \mathrm{kg}^{-1} \bullet \mathrm{min}^{-1}\right)$. These characteristics are similar to subjects in step research studies conducted previously (Holland et al., 1990; Olson et al., 1991, Thomas \& Long, 1993).

Table 2 summarizes subjects' prior use of RPE and step experience. Fourteen subjects had previously used the RPE scale and 25 subjects had not. Level of step experience was separated into three categories: 0-5 step classes $(n=6), 6-10$ classes $(n=7)$, and 11 or more classes $(n=26)$. The highest percentage of subjects (67\%) had 11 or more step classes. 
Table 1. Descriptive Characteristics for All Subjects

\begin{tabular}{|lcccccc|}
\hline & N & Mean & SD & Min & Max \\
Age (yrs) & 39 & 28.8 & 4.66 & 21.0 & 41.0 \\
Height (cm) & 39 & 164.5 & 6.09 & 152.7 & 176.7 \\
Weight (kg) & 39 & 61.5 & 14.42 & 46.7 & 108.6 \\
$\begin{array}{l}\text { VO2max } \\
\text { (ml-kg-1·min-1) }\end{array}$ & 39 & 44.3 & 7.62 & 28.8 & 61.4 \\
Body Fat (\%) & 39 & 21.6 & 4.52 & 12.5 & 30.0 \\
\hline
\end{tabular}

Table 2. Subject's Prior RPE Use and Step Experience

\begin{tabular}{|lcc|}
\hline \multicolumn{3}{c}{ No. of } \\
Subjects & $\%$ \\
Prior RPE Use & & \\
Yes & 14 & 36 \\
No & $\frac{25}{39}$ & $\frac{64}{100}$ \\
Step Experience (\# of classes) \\
$0-5$ & 6 & 15 \\
$6-10$ & 7 & 18 \\
$11+$ & $\frac{26}{39}$ & $\frac{67}{100}$ \\
\hline
\end{tabular}


Table 3 summarizes the results of heart rates at TRPE on the bench step and the treadmill. Step heart rates (STHR) were obtained by averaging the subjects' heart rates for each minute at TRPE on the bench step. Treadmill heart rates (TMHR) were obtained by averaging the subjects' heart rates for each minute at TRPE on the treadmill. Assumptions for a parametric $\underline{t}$ test including: (a) normality, (b) homogeneity, and (c) randomness of sample were checked and met. The means of $124.9 \mathrm{bpm}$ (step) and $117.8 \mathrm{bpm}$ (treadmill) demonstrated

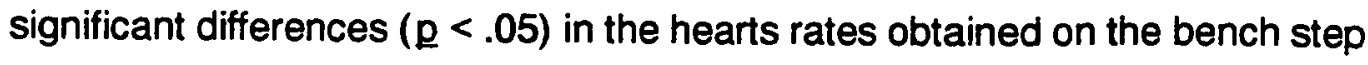
and on the treadmill. Based on the significance between means, the null hypothesis was rejected. Statistical power was estimated at .33 and the effect size at .36 due to the small sample size. Due to time, budgetary constraints, and availability of subjects, a larger sample size was not feasible. Individual heart rates on the bench step and treadmill and the differences in HRs are reported in Table 4. Visual examination of data for individuals showed that 29 subjects (74\%) had heart rates higher on the bench step at TRPE than on the treadmill, whereas 9 subjects $(23 \%)$ had lower heart rates on the bench step and one subject showed no difference. The range for the higher heart rates was 1 - 29 bpm and for the lower heart rates was 2 - 22 bpm.

\section{DISCUSSION}

\section{Heart Rates and VO2}

Using a simple random sampling method, VO2 data from eight subjects were visually examined to determine if energy costs on the bench step or the treadmill had any effect on the subject's RPE levels. Table 5 summarizes the minute by minute VE, VO2, HRs, and kcals for minutes at TRPE on the step and 


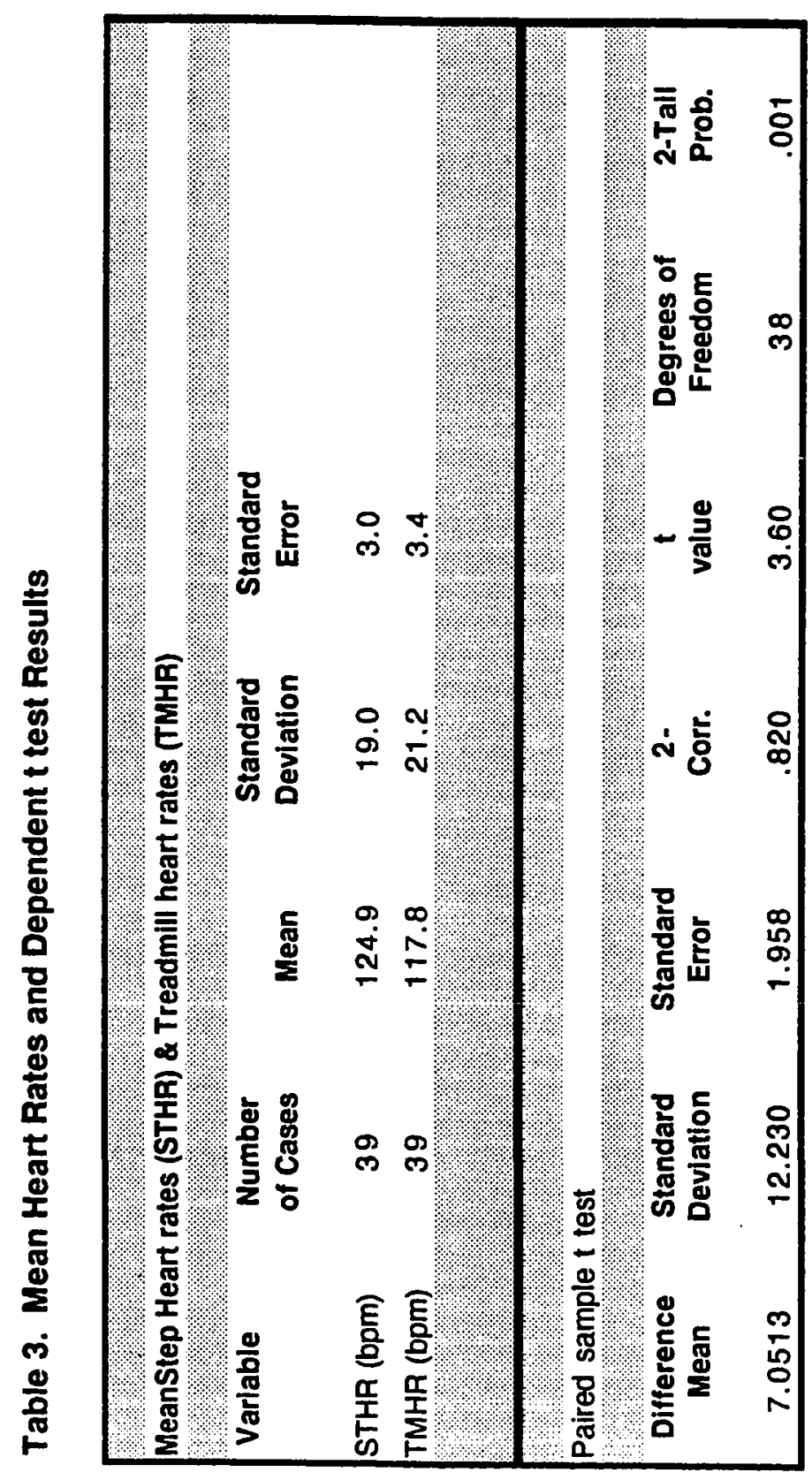


Table 4. Mean Heart Rates (HR) for All Subjects on Step and Treadmill at TRPE

\begin{tabular}{|c|c|c|c|}
\hline $\begin{array}{c}\text { ID } \\
\text { NO. }\end{array}$ & $\begin{array}{c}\text { STEP } \\
\text { Heart rate } \\
\text { (bom) }\end{array}$ & $\begin{array}{l}\text { TREADMILL } \\
\text { Heart rate } \\
\text { (bom) }\end{array}$ & $\begin{array}{c}\text { Difference } \\
\text { in HR } \\
\text { (bpm) }\end{array}$ \\
\hline 1 & 144 & 147 & -03 \\
\hline$\$ 2$ & 194 & 65 & 129 \\
\hline 8 & 182 & XY4 & WY \\
\hline 4 & 104 & 120 & -16 \\
\hline 5 & 117 & 134 & -17 \\
\hline 6 & 52 & 489 & 108 \\
\hline 8 & 108 & MOS & 808 \\
\hline 8 & 114 & 118 & -04 \\
\hline 8 & 65 & 186 & $\$ 1$ \\
\hline 10 & $1 \% 2$ & 480 & $\% 02$ \\
\hline 18 & 31 & 108 & 13 \\
\hline 18 & 105 & 987 & 180 \\
\hline 18 & 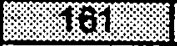 & 160 & 14: \\
\hline 14 & 132 & 132 & 0 \\
\hline 15 & 188 & 14 & $40 \%$ \\
\hline 16 & $18 \%$ & 102 & 44 \\
\hline 1 & 429 & 16 & 84 \\
\hline 18 & 822 & $\%$ & 186 \\
\hline 9 & 13 & 97 & 18 \\
\hline 20 & 184 & $101 \%$ & 208 \\
\hline 21 & 18 & Yo & 80 \\
\hline 22 & 120 & 86 & 14 \\
\hline 2 & 10 & $8 \%$ & 148 \\
\hline 24 & 15 & 18 & 180 \\
\hline 25 & 188 & Yo. & $x$ \\
\hline 26 & 100 & 89 & Yg \\
\hline 28 & 192 & S1\% & $\%$ \\
\hline 28 & 137 & 139 & -02 \\
\hline 29 & 140 & 144 & -04 \\
\hline 80 & 136 & $4 \%$ & 10 \\
\hline 31 & 124 & $1 / 8$ & 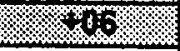 \\
\hline 32 & 128 & 138 & -10 \\
\hline 33 & 48 & 83 & 67 \\
\hline 84 & 100 & 88 & 10 \\
\hline 86 & 35 & 85 & 140 \\
\hline 39 & 13 & 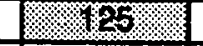 & 18 \\
\hline 38 & 127 & 149 & -22 \\
\hline 16 & 135 & 186 & 198 \\
\hline 41 & 96 & 109 & -13 \\
\hline Shadec & $\begin{array}{l}\text { ence in } h \\
\text { lad highe }\end{array}$ & 5 on step ver & \\
\hline
\end{tabular}




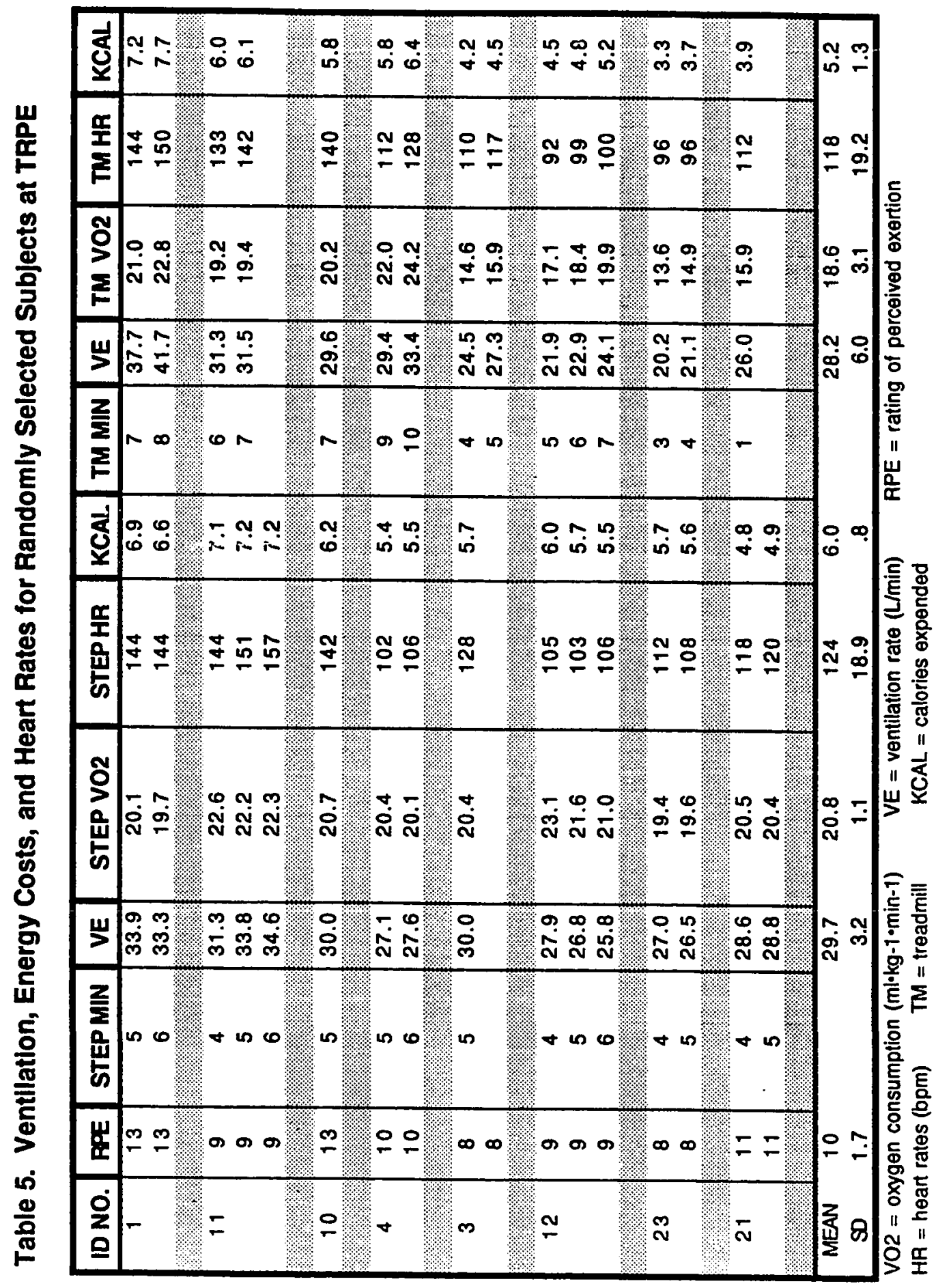


treadmill of randomly selected subjects. The energy costs were higher for those subjects experiencing higher HRs on the step which is reflected by the subjects' VO2 values, caloric expenditure (kcal) and ventilation rate (VE). Lower VO2 values on the treadmill subsequently reflected lower heart rates, kcals and ventilation rate for each subject. Even though there was a difference in VO2 values, the subjects perceived the exertion at the same level. The HRs varied as little as 2 bpm or as many as 16 bpm. Parker et al. (1989) found higher heart rates in each subject during aerobic dance exercise than during treadmill exercise when exercise was performed at the same VO2. In this study, however, the VO2 values varied with exercise modality.

To further investigate physiological variables as a possible influence on perceived exertion, minute by minute heart rate data actually achieved during the exercise testing was visually examined for each randomly selected subject (see Table 6). As an example for discussion purposes, subject 11 attained heart rates of $144,151,157 \mathrm{bpm}$ for minutes 4,5 , and 6 on the step at the TRPE of 9 . On the treadmill, this subject had heart rates of 133 and 142 at the TRPE of 9 at minutes 6 and 7 . The question is why this subject would choose an RPE of 9 at a heart rate considerably lower (144 on the step vs. 133 on the TM) than one attained previously during a different exercise modality. Thomas and Long (1993) determined that one could not rely on RPE to give a good estimate of heart rate during exercise on a bench step. A subject in their study experienced a heart rate of $180 \mathrm{bpm}$ but perceived the activity as fairly light, while another subject had a heart rate of $130 \mathrm{bpm}$ and perceived the workout as very hard. Additionally, two of the randomly selected subjects (25\%) in this study (S1 and S4) experienced lower heart rates on the step versus $75 \%$ of the subjects 
Table 6. Selected Minute by Minute Heart Rate Data for Step (ST) \& Treadmill (TM) Exercise

\begin{tabular}{|c|c|c|}
\hline I.D. No. 1 & $\mathbf{H R}$ & FPE \\
\hline \multirow{2}{*}{\multicolumn{3}{|c|}{$\begin{array}{l}\text { Step }=x p=6-10 / 198803 \\
\text { RPE }=\text { NO }\end{array}$}} \\
\hline & & \\
\hline ST MIN 4 & 148 & 11 \\
\hline ST MIN 5 & 144 & 13 \\
\hline ST MIN 6 & 144 & 13 \\
\hline & & \\
\hline TRPE & & 13 \\
\hline TM MIN 5 & 112 & 11 \\
\hline TM MIN 6 & 140 & 12 \\
\hline TM MIN 7 & 144 & 13 \\
\hline TM MIN 8 & 150 & 13 \\
\hline TM MIN 9 & 146 & 14 \\
\hline$H R=b p m$ & & \\
\hline
\end{tabular}

\begin{tabular}{|c|c|c|}
\hline I.D. No. 11 & HR & RPE \\
\hline \multicolumn{3}{|c|}{ Step exp $=1 \%$ chasses } \\
\hline \multicolumn{3}{|c|}{ RPE $=$ NO } \\
\hline ST MIN 4 & 144 & 9 \\
\hline ST MIN 5 & 151 & 9 \\
\hline ST MIN 6 & 157 & 9 \\
\hline TRPE & & 9 \\
\hline TM MIN 6 & 133 & 9 \\
\hline TM MIN 7 & 142 & 9 \\
\hline TM MIN 8 & 148 & 10 \\
\hline TM MIN 9 & 164 & 11 \\
\hline $\mathrm{HR}=\mathrm{bpm}$ & & \\
\hline
\end{tabular}

\begin{tabular}{|c|c|c|}
\hline I.D. No. 10 & $\mathbf{H}$ & PPE \\
\hline \multicolumn{3}{|c|}{ Step exp = / H classes? } \\
\hline \multicolumn{3}{|c|}{ RPE $=$ NO } \\
\hline ST MIN 4 & 140 & 12 \\
\hline ST MIN 5 & 142 & 13 \\
\hline ST MIN 6 & 146 & 14 \\
\hline TRPE & & 13 \\
\hline TM MIN 4 & 127 & 12 \\
\hline TM MIN 5 & 131 & 12 \\
\hline TM MIN 6 & i 35 & 12 \\
\hline TM MIN 7 & 140 & 13 \\
\hline TM MIN 8 & 148 & 14 \\
\hline TM MIN 9 & 152 & 15 \\
\hline $\mathrm{HR}=\mathrm{bpm}$ & & \\
\hline
\end{tabular}

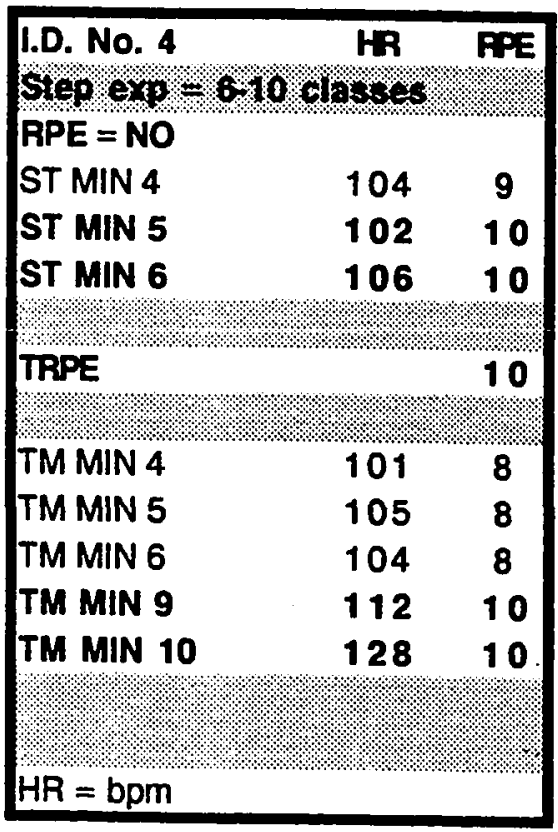


Table 6. Selected Minute by Minute Data for Step (ST) \& Treadmill (TM) Exercise (cont.)

\begin{tabular}{|c|c|c|}
\hline 1.D. No. 3 & HR & PPE \\
\hline \multicolumn{3}{|c|}{ 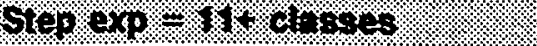 } \\
\hline \multicolumn{3}{|c|}{ RPE $=$ NO } \\
\hline ST MIN 4 & 127 & 7 \\
\hline ST MIN 5 & 128 & 8 \\
\hline ST MIN 6 & 133 & 9 \\
\hline TRPE & & 8 \\
\hline TM MIN 1 & 101 & 7 \\
\hline TM MIN 2 & 107 & 7 \\
\hline TM MIN 3 & 107 & 7 \\
\hline TM MIN 4 & 110 & 8 \\
\hline TM MIN 5 & 117 & 8 \\
\hline TM MIN 6 & 122 & 9 \\
\hline TM MIN 7 & 127 & 10 \\
\hline TM MIN 8 & 138 & 11 \\
\hline $\mathrm{HR}=\mathrm{bpm}$ & & \\
\hline
\end{tabular}

\begin{tabular}{|c|c|c|}
\hline I.D. No.12 & $\mathbf{H B}$ & RPE \\
\hline \multicolumn{3}{|c|}{ Ster $=4 \%=\%$ o dasses? } \\
\hline \multicolumn{3}{|c|}{ RPE $=$ NO } \\
\hline ST MIN 4 & 105 & 9 \\
\hline ST MIN 5 & 103 & 9 \\
\hline ST MIN 6 & 106 & 9 \\
\hline TRPE & & 9 \\
\hline TM MIN 5 & 92 & 9 \\
\hline TM MIN 6 & 99 & 9 \\
\hline TM MIN 7 & 100 & 9 \\
\hline TM MIN 8 & 103 & 10 \\
\hline TM MIN 9 & 112 & 12 \\
\hline $\mathrm{HR}=\mathrm{bpm}$ & & \\
\hline
\end{tabular}

\begin{tabular}{|c|c|c|}
\hline I.D. No. 23 & HR & RPE \\
\hline \multicolumn{3}{|c|}{ Step oxp $=4$ TH elssises } \\
\hline \multicolumn{3}{|l|}{ RPE = NO } \\
\hline ST MIN 4 & 112 & 8 \\
\hline ST MIN 5 & 108 & 8 \\
\hline ST MIN 6 & 107 & 9 \\
\hline TRPE & & 8 \\
\hline TM MIN 3 & 96 & 8 \\
\hline TM MIN 4 & 96 & 8 \\
\hline TM MIN 5 & 100 & 9 \\
\hline TM MIN 6 & 112 & 9 \\
\hline TM MIN 7 & 123 & 11 \\
\hline $\mathrm{HR}=\mathrm{bpm}$ & & \\
\hline
\end{tabular}

\begin{tabular}{|c|c|c|}
\hline I.D. NO. 21 & $\mathbf{H R}$ & PPE \\
\hline \multicolumn{3}{|c|}{ 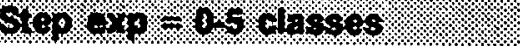 } \\
\hline \multicolumn{3}{|c|}{ RPE $=$ NO } \\
\hline ST MIN 4 & 118 & 11 \\
\hline ST MAN 5 & 120 & 11 \\
\hline ST MIN 6 & 115 & 12 \\
\hline TRPE & & 11 \\
\hline TM MIN 1 & 112 & 11 \\
\hline TM MIN 2 & 107 & 12 \\
\hline TM MIN 3 & 109 & 12 \\
\hline TM MIN 4 & 123 & 13 \\
\hline$H R=b p m$ & & \\
\hline
\end{tabular}


(S11, S10, S3, S12, S23, S21) who had experienced higher heart rates on the step. These percentages are similar to the percentages from the entire sample in this study experiencing higher heart rates on the bench step. The mean VO2 for the step was $20.8 \mathrm{ml}^{\circ} \mathrm{kg}^{-1} \cdot \mathrm{min}^{-1}$ versus $18.6 \mathrm{ml}^{\circ} \mathrm{kg}^{-1} \cdot \mathrm{min}^{-1}$ for the treadmill. The mean kcals for the step were 6.0 versus 5.3 kcals for the treadmill. When examining the physiological variables as a possible influence on perceived effort, the data suggest that VO2 and energy costs had little to do with the accurate perception of exertion for these subjects when exercising on the bench step and treadmill.

According to Dunbar et al. (1992) RPE was found to be a "valid" means of regulating exercise intensity both intra- and intermodally. However, their study set TRPE using a complex set of familiarization, estimation, and production trials. The subject was given their TRPE as a tangible value and was allowed to adjust speeds on treadmills or workloads on cycle ergometers accordingly to replicate the same exertion level. The present study, however, kept the heart rate (HR) information from the subjects. In other words, the subject had no idea as to the RPE and HR relationship. The subject's physiological responses guided their perception of exertion without the knowlege of what the TRPE value actually was. Therefore, this study is not consistent with the Dunbar et al. findings of "valid" RPE use intermodally.

Step experience, prior RPE use, and fitness level

Other possible explanations for this dissociation in heart rates and RPE levels could be attributable to step experience, prior use of the RPE scale and/or overall fitness level. 
When exploring step experience as a possible explanation for the higher heart rates on the step as opposed to the treadmill, the data provided the percentages shown in Table 7. Those subjects having 11 or more step classes had the greatest percentage $(81 \%)$ of higher heart rates on the step versus the treadmill. Therefore, the majority of subjects in this study with greater step experience had a decreased perception of exertion actually achieved physiologically on the step. This could be attributable to a psychological feeling of ease due to the familiarity with this type of exercise.

When exploring the possibility of prior RPE use having an effect on the subject's responses, visual inspection of the results in this study showed little percentage difference between groups in obtaining higher HRs on the step and on the treadmill (see Table 8). Thus, prior use of the RPE scale did not appear to influence the subject's perception of exertion on the step versus the treadmill.

When taking into consideration the factor of fitness level using $\mathrm{VO}_{2 \max }$ data, the subjects in this group were rated overall in the "good" category as indicated for the age group 20-29 years (Heyward, 1991). In the high fit group

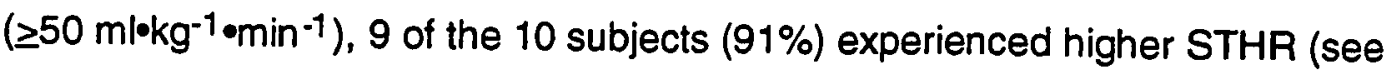
Table 9). When adding step experience to the variable of fitness level, 7 of the 8 subjects $(88 \%)$ in the high fit category experienced higher heart rates on the bench step. It appears for the subjects in this study, possessing higher fitness levels and greater step experience resulted in a lowered perceived exertion while exercising on the step. The $40-49 \mathrm{ml}^{\circ \mathrm{kg}^{-1}} \mathrm{~min}^{-1}$ group had $65 \%$ of their subjects experience higher STHR. While the subjects in the lowest $\mathrm{VO}_{2 \max }$ group also had a greater percentage of subjects (72\%) experiencing higher heart rates on 
Table 7. Number of Subjects with Higher Step \& Treadmill Heart Rates Based on Step Experience

\begin{tabular}{|c|c|c|c|c|c|c|}
\hline STEP EXP* & $\begin{array}{l}\text { SUBJECTS WI } \\
\text { HIGHER STHRS }\end{array}$ & $\%$ & $\begin{array}{l}\text { SUBJECTS WI } \\
\text { HIGHER TMHRs }\end{array}$ & $\%$ & $\begin{array}{c}\text { No } \\
\text { Change }\end{array}$ & $\%$ \\
\hline $0-5$ & 4 & 67 & 2 & 33 & & \\
\hline $6-10$ & 4 & 57 & 3 & 43 & & \\
\hline$\ldots \ldots \ldots$ & 19.9. & : : & & & & \\
\hline $11+$ & 21 & 81 & 4 & 15 & 1 & 4 \\
\hline \multicolumn{7}{|c|}{ No. of classes } \\
\hline \multicolumn{7}{|c|}{ STHRS = Step Heart Rates } \\
\hline 1 & & & I & & & \\
\hline
\end{tabular}

Table 8. Number of Subjects with Higher Step \& Treadmill Heart Rates Based on Prior RPE Use

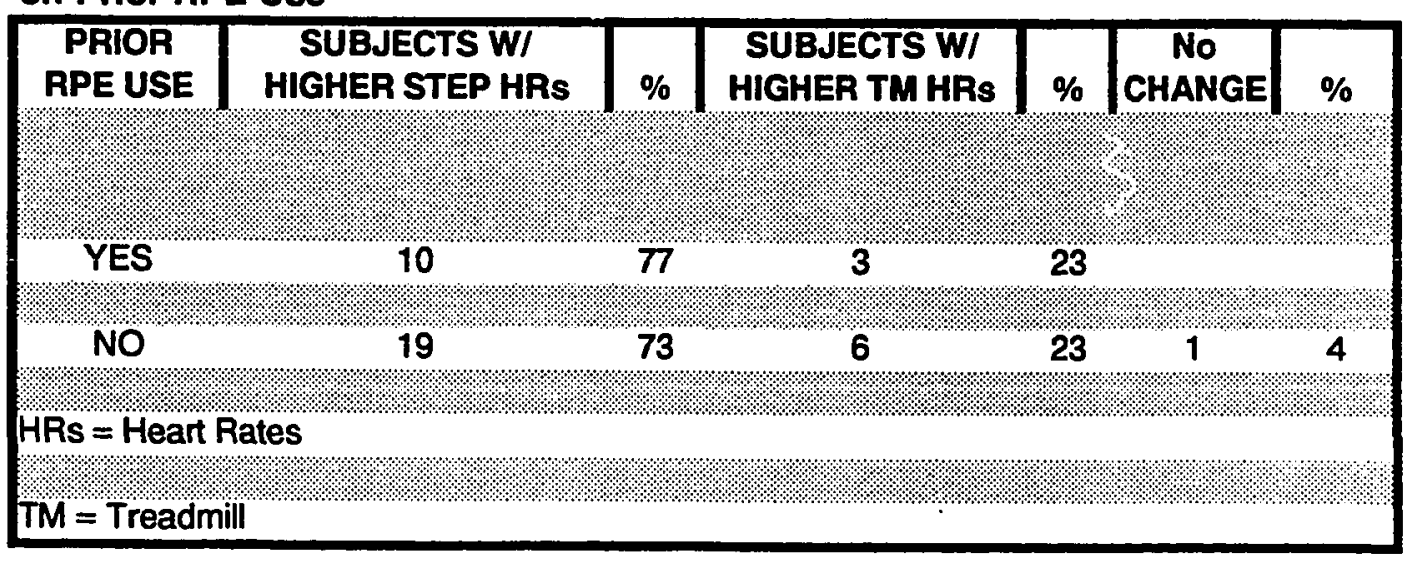


Table 9. VO2max Data for All Subjects

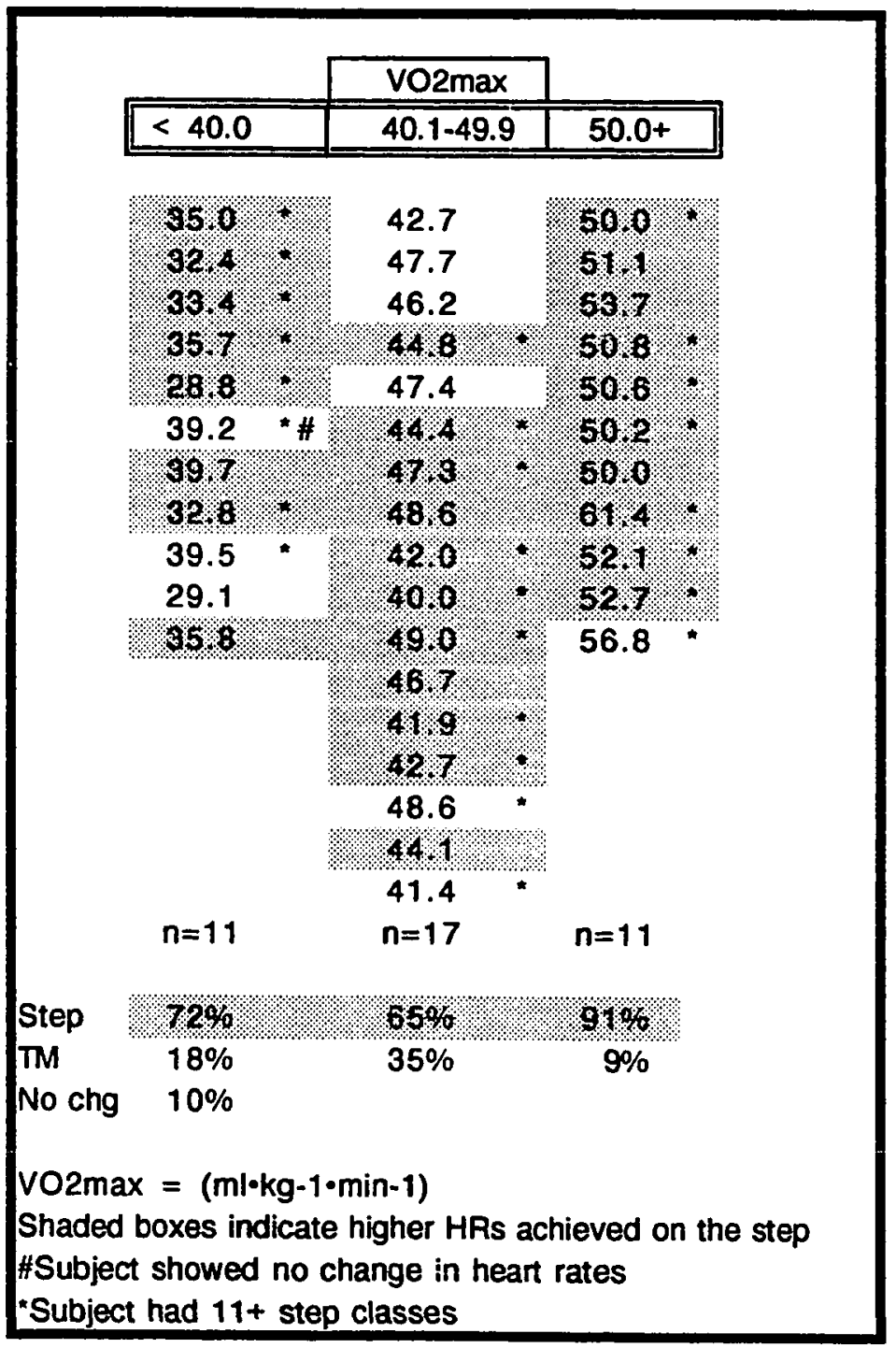


the step. When adding in the variable of step experience to the subjects HR responses in the $40-49 \mathrm{ml}^{\circ \mathrm{kg}^{-1} \cdot \mathrm{min}^{-1}}$ group and to the under $40 \mathrm{ml}^{\circ} \mathrm{kg}^{-1} \cdot \mathrm{min}^{-1}$ group, the percentages are $73 \%$ and $88 \%$ respectively for the subjects achieving higher heart rates on the step. This data might suggest that fitness level alone does not affect the perception of effort for these subjects with the exception of the high fit group. However, when combining the variable of step experience with the variable of fitness level, these subjects' perception of effort may have been affected.

\section{Psychological Phenomenon}

According to Morgan (1994), there has been a dichotomous school of thought on the subjeci of perceived exertion. Physiologists tend to regard the perception of effort as a psychological phenomenon whereas psychologists support the idea of using physiological variables as a basis for determining perceived exertion. The general consensus is to combine these thoughts and view perceived exertion in a psychophysiological sense or a mind-body context. Morgan further stated that the perception of effort can also be influenced by factors such as gender, personality structure, and training status.

With regard to training status as determined by $\mathrm{VO}_{2 \max }$ in this study, it has been addressed in the previous discussion. It was suggested by the results of a subsample not to have an effect on the perception of effort. Since only females were included in this study, there is no evidence available to substantiate the claim of gender as a factor in perception of effort. Morgan (1994) also investigated psychological variables such as anxiety, neuroticism, depression, extroversion, and stait and trait anxiety. To further explore the psychological variables as possible influences on perceived exertion, this study can assess to 
some degree the subjects' disposition based on comments made during exercise testing. It can be assumed that subjects may have been anxious or nervous about performing the exercise tests. Several subjects stated, "I'm nervous" or "I've never done this before." For many of them, it was the first time they had participated in a research study and performed exercise to exhaustion in the form of a graded exercise test. Possibly, the thought of having to exercise to exhaustion on the treadmill influenced the subject's perception of effort as harder as opposed to performing "just" a six minute step test. Also, there were subjects who experienced some discomfort with the mouth piece and nose clip necessary for gas analysis which had to be worn for a greater length of time during treadmill testing.

As for the other variables Morgan (1994) investigated, this study did not measure those parameters and cannot substantiate or investigate his claims. With one exception, a subject did report the daily ingestion of a psychotropic drug. Certainly not compelling evidence to include the variable of depression as a factor affecting the perception of effort in this study.

\section{RPE}

The results of this study indicate that the use of RPE as a means of regulating exercise intensity will not accurately transfer across exercise modalities, specifically the step and treadmill. However, the use of RPE as a successful indicator of perceived effort and as an adjuvant to exercise prescription is addressed by Dishman (1994). Dishman cited several authors that reported a correction factor of 20 to $30 \mathrm{bpm}$ must be added for RPEs of 11 16 and heart rates within $130-160 \mathrm{bpm}$. Table 10 describes minute at TRPE on the bench step and treadmill, the corresponding heart rates, TRPE, and adjusted 
Table 10. RPE Correction Factor for Subjects with Heart Rates (HR) within Adjusted Heart Rate Range at TRPE

\begin{tabular}{|c|c|c|c|c|c|c|}
\hline SUB. NO. & STEPMN & $\begin{array}{c}\text { STEP } \\
\text { HR (BPM) }\end{array}$ & TMMIN & $\begin{array}{l}\text { TREADAN } \\
\text { HR (BPM) }\end{array}$ & TRPE & ADUUSTED HR \\
\hline \multirow[t]{2}{*}{1} & 5 & 144 & 7 & 144 & 13 & $150-160$ \\
\hline & 6 & 144 & 8 & 150 & 13 & \\
\hline & & & & & ঝ & \\
\hline \multirow[t]{3}{*}{6} & 4 & 148 & 6 & 142 & 12 & $140-150$ \\
\hline & 5 & 156 & 7 & 150 & 12 & \\
\hline & & & 8 & 156 & 12 & \\
\hline & & & & & & \\
\hline \multirow[t]{2}{*}{14} & 5 & 130 & 9 & 132 & 11 & $130-140$ \\
\hline & 6 & 133 & & & 11 & \\
\hline & & & & & \%. & \\
\hline \multirow[t]{2}{*}{26} & 5 & 169 & 5 & 148 & 12 & $140-150$ \\
\hline & 6 & 167 & 6 & 150 & 12 & \\
\hline & & & & ঋে? & & \\
\hline \multirow[t]{2}{*}{30} & 4 & 136 & 1 & 112 & 11 & $130-140$ \\
\hline & 5 & 136 & 2 & 122 & 11 & \\
\hline & & ঝి & & & & \\
\hline \multirow[t]{4}{*}{32} & 4 & 129 & 11 & 135 & 11 & $130-140$ \\
\hline & 5 & 136 & 12 & 136 & 11 & \\
\hline & 6 & 120 & 13 & 136 & 11 & \\
\hline & & & 14 & $\uparrow 44$ & 11 & \\
\hline \% & & & & & & \\
\hline \multirow[t]{3}{*}{37} & 4 & 136 & 1 & 120 & 11 & $130-140$ \\
\hline & 5 & 133 & 3 & 130 & 11 & \\
\hline & 6 & 142 & & & 11 & \\
\hline & & & & & & 1. \\
\hline \multirow[t]{3}{*}{38} & 4 & 123 & 6 & 149 & 11 & $130-140$ \\
\hline & 5 & 128 & & & 11 & \\
\hline & 6 & 131 & & & 11 & \\
\hline \multicolumn{7}{|c|}{ 'BASED ON RPE CORRECTION FACTOR: RPE X $10+20$ to $30 \mathrm{BPM}$} \\
\hline & (a) & & & & & \\
\hline
\end{tabular}


heart rates for subjects having a TRPE of 11-16. After careful visual examination of all subjects' data from this study, 18 of the 39 subjects ( $46 \%$ ) had a TRPE in the range of $11-16$. Applying the correction factor of 20 to $30 \mathrm{bpm}$ to these subject's heart rates, 8 of the 18 subjects (44\%) had heart rates within the adjusted heart rate range as proposed by Dishman on at least one mode of activity. The remaining 10 subjects with TRPEs of $11-16$ are depicted in Table 11 , however these subjects did not possess heart rates within the adjusted heart rate range.

Further Dishman (1994) stated, "it is expected that reproduction of an intensity will be more accurate if the estimation task is intramodal rather than intermodal" (p. 1089). Interestingly, four of the eight subjects (50\%) had heart rates within the adjusted heart rate range on only one exercise modality. Of those four subjects, two achieved these heart rates on the step and two achieved these heart rates on the treadmill. The results of this study thus far do not appear to offer conclusive evidence to corroborate Dishman's findings.

Dishman (1994) also stated, "RPE estimates appear to be more accurate at higher intensities" (p. 1089). In this study, target RPEs were determined by the 6 minute submaximal step test with heart rates in the range of $93-169 \mathrm{bpm}$. TRPE ranged from $7-13$, with a mean of 10 , corresponding to very, very light and somewhat hard activity on Borg's perception scale. These lower intensities couldpossibly explain the under-estimation of perceived effort on the step by those subjects with heart rates exceeding treadmill heart rates at TRPE. 
Table 11. RPE Correction Factor for Subjects Whose Heart Rates (HR) were Outside the Adjusted Heart Rate Range at TRPE

\begin{tabular}{|c|c|c|c|c|c|c|}
\hline SUB. NO. & STEPMN & $\begin{array}{c}\text { STEP } \\
\text { HR (BPM) }\end{array}$ & TMMIN & $\begin{array}{l}\text { TREADMM } \\
\text { HR (BPM) }\end{array}$ & TRPE & ADJUSTED HR' \\
\hline 8 & $\begin{array}{l}5 \\
6\end{array}$ & $\begin{array}{l}109 \\
118\end{array}$ & $\begin{array}{c}6 \\
7 \\
8 \\
9 \\
10\end{array}$ & $\begin{array}{l}111 \\
111 \\
118 \\
128 \\
122\end{array}$ & $\begin{array}{l}11 \\
11 \\
11 \\
11 \\
11\end{array}$ & $130-140$ \\
\hline 9 & 4 & 162 & 4. & 138 & 12 & $140-150$ \\
\hline 10 & 5 & 142 & 7 & 140 & 13 & $150-160$ \\
\hline 15 & $\begin{array}{l}5 \\
6\end{array}$ & $\begin{array}{l}117 \\
118\end{array}$ & 6 & 117 & $\begin{array}{l}12 \\
12\end{array}$ & $140-150$ \\
\hline 21 & $\begin{array}{l}4 \\
5\end{array}$ & $\begin{array}{l}118 \\
120\end{array}$ & 1 & 112 & $\begin{array}{l}1 \% \\
11 \\
11\end{array}$ & $130-140$ \\
\hline 24 & $\begin{array}{l}4 \\
5\end{array}$ & $\begin{array}{l}112 \\
117\end{array}$ & $\begin{array}{c}7 \\
8 \\
9 \\
10\end{array}$ & $\begin{array}{l}110 \\
109 \\
114 \\
109\end{array}$ & $\begin{array}{l}11 \\
11 \\
11 \\
11\end{array}$ & $130-140$ \\
\hline 29 & 5 & 140 & 5 & 144 & 13 & $150-160$ \\
\hline 31 & $\begin{array}{l}5 \\
6\end{array}$ & $\begin{array}{l}122 \\
125\end{array}$ & $\begin{array}{l}5 \\
6\end{array}$ & $\begin{array}{l}117 \\
118\end{array}$ & $\begin{array}{l}12 \\
12\end{array}$ & $140-150$ \\
\hline 36 & $\begin{array}{l}4 \\
5\end{array}$ & $\begin{array}{l}95 \\
95\end{array}$ & $\begin{array}{l}1 \\
2 \\
3 \\
4 \\
5 \\
6\end{array}$ & $\begin{array}{l}85 \\
82 \\
80 \\
85 \\
88 \\
91\end{array}$ & $\begin{array}{l}11 \\
11 \\
11 \\
11 \\
11 \\
11\end{array}$ & $130-140$ \\
\hline 41 & $\begin{array}{l}5 \\
6\end{array}$ & $\begin{array}{l}95 \\
96\end{array}$ & $\begin{array}{c}7 \\
8 \\
9 \\
10\end{array}$ & $\begin{array}{l}106 \\
106 \\
111 \\
113\end{array}$ & $\begin{array}{l}13 \\
13 \\
13 \\
13\end{array}$ & $150-160$ \\
\hline
\end{tabular}


Summary of Findings

1) Significant differences existed in heart rates at TRPE on the step and the treadmill, supporting rejection of the null hypothesis at a significance level of $\mathrm{p}<.05$.

2) VO2 and energy costs appeared to have little effect on the perception of exertion for the subjects in this study.

3) This study did not corroborate the use of RPE intermodally.

4) Prior RPE use did not appear to have an effect on the perception of effort experienced by these subjects.

5) This study did not offer conclusive evidence to substantiate the correction factor of adding 20 to $30 \mathrm{bpm}$ to subject's heart rates at TRPE. Although, $21 \%$ of subjects fell within the parameters for using this method.

6) The lower intensities used in this study may have influenced the perception of effort experienced by these subjects.

7) With regard to this research study, most subjects had heart rates on the bench step indicating much greater physiological stress than perceived exertion values indicated. 


\section{CHAPTER FIVE}

\section{SUMMARY, CONCLUSIONS, AND RECOMMENDATIONS Summary}

The focus of this study was to determine if differences existed in heart rates at a target rating of perceived exertion (TRPE) during step and treadmill exercise. Forty-two female subjects were recruited from San Jose State University and local area health clubs. Subjects ranged in age from 21 to 41 years of age, were in good overall health, had no history of significant musculoskeletal injuries, coronary heart disease, or contraindications for exercise. All subjects completed all testing which included a six minute submaximal step test at a cadence of $120 \mathrm{bpm}$ and a maximal graded exercise test on the treadmill. However, data from three subjects were not used in the data analysis procedures due to failure to obtain the TRPE on the treadmill portion of the exercise testing. Subject's heart rates were continuously monitored and recorded during the last 10 seconds of minutes 4,5 , and 6 on the step test and for each minute on the treadmill portion of the testing. Ratings of perceived exertion (RPE) were taken during the last 10 seconds of minutes 4,5 , and 6 on the step test and during the last 10 seconds for each minute or portion thereof on the treadmill test.

Significant differences in mean heart rates were determined for step versus treadmill at TRPE as determined by a dependent $₫$ test. Statistical power was estimated at .33 and the effect size at .36 due to the small sample size. Due to time, budgetary constraints, and availability of subjects, a larger sample size was not feasible. Also, measurement precision is a factor that affects power. Subjects were tested one time only, possibly affecting the reliability of the heart 
rates and RPEs. The tests perhaps should have been repeated over time to assess stability.

\section{Conclusions}

Based on the results of this study and within its limitations, the following conclusions were reached:

1. Perception of effort (as evidenced by RPE) is lower during step exercise than physiologically achieved as indicated by higher heart rates at a given RPE while exercising on the bench step versus the treadmill.

2. Based on visual inspection, subject's prior knowledge and use of the RPE scale did not appear to influence the perception of exertion intermodally.

3. Based on visual inspection, the subject's fitness level alone did not appear to be an indicator for RPE accuracy. However, when fitness level was combined with step experience, a majority of subjects perceived a lower rate of exertion while exercising on the bench step.

\section{Recommendations}

The following recommendations are proposed for future research.

1. A larger sarnple size $(n=132)$ as calculated by the power program will improve power for a similar study.

2. Both males and females should serve as subjects to determine if gender affects perceived exertion and the intermodal use of RPE.

3. Further investigate the correction factor of $20-30 \mathrm{bpm}$ added to heart rates within 130-160 bpm for RPEs of 11-16 on the Borg scale. 
4. Determine if psychological variables such as anxiousness, nervousness, and depression should be investigated in the form of a survey for effects on perceived exertion.

5. A protocol should be designed to control for varying intensities between exercise modalities. The slow speeds and steep grades used during the treadmill test may have affected RPEs. Increasing the exercise intensity on the step and using a standard treadmill protocol may yield more accurate results.

6. A potential order effect may have affected the results of this study, therefore target RPEs should be established in a separate test session and/or a counter balanced design should be employed.

7. Reliability of heart rates should be investigated to further substantiate the use of RPE to monitor exercise intensity. 


\section{REFERENCES}

Aldridge, M. (1990, May). To step or not to step. Fitness ivianagement, pp. $32-$ 36.

Ahlquist, L., Samuels, J., Ward, A., Puleo, E., Unnithan, V., \& Rippe, J. (1991).

A submaximal step test which predicts $\mathrm{VO}_{2 \max }$ using stepwise multiple regression. Supplement to Medicine and Science in Sports and Exercise, $1991,23(4)$, Abstract No. 74.

American College of Sports Medicine. (1991). Guidelines for exercise testing and prescription. Philadelphia: Lea \& Febiger.

American College of Sports Medicine. (1990). The recommended quantity and quality of exercise for developing and maintaining cardiorespiratory and muscular fitness in healthy adults. Position Statement. Medicine and Science in Sports and Exercise, 22, 265-274.

Berry, M. J., Cline, C. C., Berry, C. B., \& Davis, M. (1992). A comparison between two forms of aerobic dance and treadmill running. Medicine and Science in Sports and Exercise, 24(8), 946-951.

Birk, T. J., \& Birk, C. A. (1987). Use of ratings of perceived exertion for exercise prescription. Sports Medicine, 4, 1-8.

Borg, G. A. (1982). Psychological bases of physical exertion. Medicine and Science in Sports and Exercise, 14(5), 377-381.

Borg, G., \& Ottoson, D. (Eds.) (1986). The perception of exertion in physical work. London: MacMillan.

Bryant, C. X., and Peterson, J. A. (1992, August). Estimating aerobic fitness. Fitness Management, pp. 36-39. 
Ceci, R., \& Hassmen, P. (1991). Self-monitored exercise at three different RPE intensities in treadmill vs field running. Medicine and Science in Sports and Exercise, 23(6), 732-738.

Dishman, R. K. (1994). Prescribing exercise intensity for healthy adults using perceived exertion. Medicine and Science in Sports and Exercise 26(9), 10871094.

Dishman, R. K., Patton, R. W., Smith, J., Weinberg, R., \& Jackson, A. (1987). Using perceived exertion to prescribe and monitor exercise training heart rate. International Journal of Sports Medicine, 8(3), 208-213.

Dunbar, C. C., Robertson, R. J., Baun, R., Blandin, M. F., Metz, K., Burdett, R., \& Goss, F. L. (1992). The validity of regulating exercise intensity by ratings of perceived exertion. Medicine and Science in Sperts and Exercise, 24 (1), 9499.

Eston, R. G., Davies, B. L., \& Williams, 1. G. (1987). Use of perceived effort ratings to control exercise intensity in young healthy adults. European Journal of Applied Physiology, 56, 222-224.

Eston, R. G., \& Williams, J. G. (1988). Reliability of ratings of perceived effort for regulation of exercise intensity. British Journal of Sports Medicine, 22, 153-154.

Francis, P. R. (1990, May). In step with science. Fitness Management, pp. 3738.

Fox, E. L., Bowers, R. W., \& Foss, M. L. (1989). The physiological basis of physical education and athletics (4th ed). Dubuque: Wm. C. Brown Publishers. 
Glass, S. C., Knowiton, R. G., \& Becque, M. D. (1992). Accuracy of RPE from graded exercise to establish exercise training intensity. Medicine and Science in Sports and Exercise, 24(11), 1303-1307.

Glass, S. C., Whaley, M. H., \& Wegner, M. S. (1991). Ratings of perceived exertion among standard treadmill protocols and steady state running. International Journal of Sports Medicine, 12(1), 77-82.

Harste, A. (1990). Bench aerobics: A step in the right direction? The Physician and Sportsmedicine, 18(7), 25-26.

Heyward, V. H. (1991). Advanced Fitness Assessment \& Exercise Prescription (2nd ed.) Champaign, IL: Human Kinetics Books.

Holland, G. J., Hoffmann, J. J., Vincent, W., Mayers, M., \& Caston, A. (1990). Treadmill vs step treadmill ergometry. The Physician and Sportsmedicine, $18(1), 79-84$.

Hornsby, G., Dixon, M., Anderson, J., \& East, W. (1991). Variations in $\mathrm{VO}_{2}$ for three dance-exercise videotapes performed at the same mean heart rate. Supplement to Medicine and Science in Sports and Exercise, 1991, 23(4), Abstract No. 842.

Jackson, A., Pollock, M., and Ward, A. (1980). Generalized equations for predicting body density for women. Medicine and Science in Sports and Exercise, 12, 175-182.

Karvonen, J., \& Vuorimaa, T. (1988). Heart rate and exercise intensity during sports activities. Sports Medicine, 5, 303-312.

Matheny, S. L., \& Swain, D. P. (1991). Heart rate and oxygen consumption responses to incremental exercise in men versus women. Supplement to Medicine and Science in Sports and Exercise, 1991, 23(4), Abstract No. 844. 
McArdle, W. D., Katch, F. I., \& Katch, V. L. (1991). Exercise physiology: Energy, nutrition, and human performance (3rd ed.) Philadelphia: Lea \& Febiger.

Monahan, T. (1988). Perceived exertion: An old exercise tool finds new applications. The Physician and Sportsmedicine, 16(10), 174-179.

Morgan, W. P. (1994). Psychological components of effort sense.

Medicine and Science in Sports and Exercise, 26(9), 1071-1077.

Nethery, V. M. (1992). Effect of exercise intensity and duration on sensory manipulation of perceived exertion. Supplement to Medicine and Science in Sports and Exercise, 24(5), Abstract No. 807.

Noble, B. (1982). Clinical applications of perceived exertion. Medicine and Science in Sports and Exercise, 14(5), 406-411.

Olson, M. S., Williford, H. N., Blessing, D. L., \& Greathouse, R. (1991).

Cardiorespiratory responses to "aerobic" bench stepping exercise in females. Supplement to Medicine and Science in Sports and Exercise. 1991, 23 (4), Abstract No. 159.

Parker, S. B., Hurley, B. F., Hanlon, D.P., \& Vaccaro, P. (1989). Failure of target heart rate to accurately monitor intensity during aerobic dance. Medicine and Science in Sports and Exercise, 21(2), 230-234.

Reeves, B. D., \& Darby, L. A. (1991). Comparison of $\mathrm{VO}_{2}$ and heart rate responses of college females during graded exercise tests: Treadmill vs. dance exercise. Supplement to Medicine and Science in Sports and Exercise, 1991, 23(4), Abstract No. 843. 
Ricard, R. M., Leger, L., \& Massicotte, D. (1990). Validity of the "220-age" formula to predict maximal heart rate. Supplement to Medicine and Science in Sports and Exercise, 1990, 22(2), Abstract No. 575.

Robertson, R. J. (1982). Central signals of perceived exertion during dynamic exercise. Medicine and Science in Sports and Exercise, 14(5), 390-396.

Robertson, R. J., Goss, F. L., Auble, T. E., Cassinelli, D. A., Spina, R. J., Glickman, E. L., Galbreath, R. W., Silberman, R. M., \& Metz, K. F. (1990). Cross-modal exercise prescription at absolute and relative oxygen uptake using perceived exertion. Medicine and Science in Sports and Exercise, 22 (5), 653659.

Ryschon, T., Kemp, M., \& Johnson, S. (1991). Relationship between heart rate during submaximal stepping and $\mathrm{VO}_{2}$ in pre-pubescent children. Supplement to Medicine and Science in Sports and Exercise, 1991, 23(4), Abstract No. 73.

Samuels, J., Ahlquist, L., Ward, A., Puleo, E., Unnithan, V., \& Rippe, J. (1991). Development of a submaximal step test to estimate $\mathrm{VO}_{2 \max }$ using the Life Fitness Lifestep. Supplement to Medicine and Science in Sports and Exercise, 1991, 23(4), Abstract No. 71.

Stanforth, D., Hamman, C., \& Senechal, C. (1988). Relationship of heart rate and oxygen consumption during low impact aerobic movements. Supplement to Medicine and Science in Sports and Exercise, 1988, 20(3), Abstract No. 526. Thomas, D. Q., \& Long, K. A. (1993). Heart rate and rating of perceived exertion responses to aerobic bench training. Journal of Strength and Conditioning Research, Z(2), 90-94. 
Thomas, S. G., Weller, I. M. R., \& Cox, M. H. (1993). Sources of variation in oxygen consumption during a stepping task. Medicine and Science in Sports and Exercise, 25(1), 139-144.

Thomas, T. R., \& Londeree, B. R. (1989). Energy cost during prolonged walking vs. jogging exercise. The Physician and Sportsmedicine, 17(5), 93-102.

Thompson, N. N., \& Foster, C. (1990). Prediction of exercise training intensity using rating of perceived exertion. Supplement to Medicine and Science in Sports and Exercise, 1990, 22(2), Abstract No. 10.

Velasquez, K. S. and Wilmore, J. H. (1992). Changes in cardiorespiratory fitness and body composition after a 12-week bench step training program. Supplement to Medicine and Science in Sports and Exercise, 1992, 24 (5), Abstract No. 464.

Whaley, M. H., Woodall, M. T., Kaminsky, L. H., \& Emmett, J. (1992). The RPEHR relationship varies among treadmill test protocols and steady state exercise in the field setting. Supplement to Medicine and Science in Sports and Exercise, 1992, 24(5), Abstract No. 993. 


\section{APPENDICES}


APPENDIX A

\section{HEALTH HISTORY QUESTIONNAIRE}

This form constitutes an application to the San Jose State University, Department of Human Performance, Master's thesis study. All information will be kept confidential. This information will be used in evaluating your readiness for exercise. Please make this record as accurate and complete as possible. Print or type for easy legibility.

Name Address City, State, Zip

Phone: Day Evening:

Personal Physician (local):

Phone: Address:

Person to Contact in Case of an Emergency:

Relationship to you:

Daytime Phone \#:

Demographic Information:

Age (yrs) Gender

Height (ins) Weight (lbs)

Medical Information (Check if yes)

Past History: In the past have you ever had:

Heart attack or stroke

Heart surgery

Disease of arteries

Injuries to back, knees, ankles

Allergic reactions

Asthma

Unusual dizziness

Anemia

Elevated cholesterol

Rheumatic fever
Heart rhythm problems
Varicose veins
Epilepsy or convulsions
Tuberculosis
Arthritis
Fainting spells
Thyroid problems
Hernias

Family History: Have any blood relatives had: (include parents, sisters, brothers, grandparents)

\begin{tabular}{|l|l}
\hline $\begin{array}{l}\text { Heart attack under age 50 } \\
\text { High blood pressure } \\
\text { Congenital heart disease }\end{array}$ & $\square \begin{array}{l}\text { Strokes under age } 50 \\
\text { High cholesterol } \\
\text { Asthma or hay fever }\end{array}$ \\
\hline
\end{tabular}

\begin{tabular}{|l} 
\\
Heart murmur \\
High blood pressure \\
Lung disease \\
Diabetes \\
Bronchitis \\
Abnormal chest X-ray \\
Scarlet fever \\
Urinary tract problems \\
None of the Above
\end{tabular}

Present Symptoms: Have you recently (in the past 6 months) had:
Chest pain or pressure
Light headedness
Back pain
Awakened short of breath
Chronic muscle soreness

Shortness of breath

Cough on exertion

Arthritis

Loss of consciousness

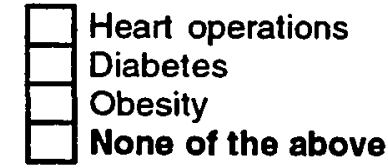

$\square$ Heart palpitations Coughing up blood Swollen legs Joint soreness None of the above 
Please explain any conditions checked above (specific condition, date of event, etc).

(cont. on next page)

List prescribed or self-prescribed medicatioris or diet supplements you now take.

Date of last complete physical exam (month, year):

( ) can't

remember

Date of last chest $X$-ray (month, year):

Date of last electrocardiogram (ECG) (month, year):

( ) can't remember remember

Were any of the above abnomal? ( ) yes ( ) no

Have you ever had any major chronic skeletal or muscular injuries? ( ) y ( ) no If yes, explain:

List any hospitalization in past 10 years, include dates and reasons for hospital stay:

List any allergies you have (including drug allergies):

Explain any other significant medical problem that you consider important for us to know.

\section{Lifestyle Information}

Have you ever smoked cigarettes, cigars or a pipe? ( ) yes ( ) no

Do you presently smoke? ( ) yes ( ) no If no, when did you quit ? (year)

Do you drink caffeinated beverages? ( ) yes ( ) no If yes, which ones.... cups per day.

Are you currently involved in a regular exercise program? ( ) yes ( ) no If yes indicate the kind of activity and number of days per week: 
Do you regularly engage in aerobic activity (e.g., walking, running, cycling, swimming, aerobic dance, etc) for 20 minutes or longer at least 3 days each week? ( )yes ( ) no

Do you frequently participate in competitive sports? ( ) yes ( ) no

If yes, which one(s)?

Step Exercise Participation: ( ) yes ( ) no ___ \# of classes days per week.

How would you describe your general health?

( ) poor ( ) fair ( ) average ( ) good ( ) excellent

Have you ever been advised by a physician not to exercise because of a medical problem? ( ) yes ( ) no if yes, please explain:

I certify that, to the best of my knowledge, the above answers are accurate and true.

Signature

Date

For office use only:

Risk factor evaluation by 
APPENDIX B

\section{INFORMED CONSENT FORM}

\section{AGREEMENT TO PARTICIPATE IN RESEARCH}

Responsible Investigator: Barbara Love

Title of Protocol: Comparison of Responses to Bench Step and Treadmill Exercise.

1. I have been asked to participate in a research study to examine responses to exercise on a bench step and a treadmill.

2. I will be asked to complete a health history and step exercise experience questionnaire, an agreement to participate in the research, a step test, a maximum treadmill test and have the following measurements taken: height, weight, skinfold measurements, resting blood pressure and resting heart rate at San Jose State University during Spring 1994.

3. Possible risks and/or Discomforts: You may experience some discomfort and/or dryness in the mouth, throat and chest during exercise on the bench step and/or treadmill. You may feel lightheaded or fatigued for a short time following these procedures. You may experience an increased heart rate and breathing rate, sweating, and an increased body temperature. Discomfort and/or redness may result from the electrocardiogram electrodes during testing. During high intensity exercise, abnormal heart beats may occur. If abnormalities are detected in electrocardiographic recordings, the test will be stopped immediately and you will not be included as a subject in this study. There may be some bruising or pinching from skinfold measurements.

4. I will benefit from participation in this study by receiving information regarding body composition, physical characteristics (height, weight and resting blood pressure) and aerobic fitness level. This study will provide information to assist aerobics instructors in determining appropriate guidelines for prescribing intensity of exercise.

5. All data collected from this research study may be used for medical and/or scientific purposes, including publication and presentation at professional conventions and events. My identity for individual test results will not be revealed in published or presented papers without my written consent.

6. I understand that I will not be compensated for my participation in this study.

7. Any questions about the research may be addressed to Barbara Love (principal investigator), at (415) 854-2774. Complaints about the research may be presented to Dr. James Bryant, Chairman of Department of Human Performance, at (408) 924-3010. Questions or complaints about research, 
subjects' rights, or research-related injury may be presented to Serena Stanford, Ph.D., Associate Vice President of Graduate Studies and Research, at (408) 924-2480.

8. No service of any kind, to which I am otherwise entitled, will be lost or jeopardized if I choose to "not participate" in the study.

9. Having read the above, I agree that my consent is given voluntarily without being coerced. I understand that I may withdraw from this study at any time (including during testing), without prejudice to my relations with the Department of Human Performance, San Jose State University, the principal investigator, or their associates.

10. I understand that I have received a signed and dated copy of the consent form. The returned copy of this consent from indicates agreement and confirmation of my being included as a participant in this study, and that I agree that I have been fully informed of my rights.

My signature indicates that I have agreed to participate in this study. 


\section{VOLUNTEER SUBJECTS NEEDED FOR STEP EXERCISE STUDY* \\ *data to be collected this summer}

Barbara Love, candidate for a Master of Arts at San Jose State University, majoring in Exercise Physiology, will be conducting research that measures response to exercise on a bench step and treadmill.

Testing includes:

- estimate of body fat

- measurement of aerobic fitness

(VO2max using a treadmill test)

- assessment of resting blood pressure.

If you are female, 21-41 years of age, in good overall health, have no history of coronary heart disease or significant musculoskeletal injuries, have attended at least 8 step classes and are interested in being a subject, call Barbara Love at (415) 854-2774. 


\section{APPENDIX D}

\section{PRE-TEST INSTRUCTIONS}

Report to: San Jose State University Human Performance Exercise Physiology and Biomechanics Laboratory, Building SPXC, Room 208. If you cannot make the testing time, please call Barbara Love in advance at (415) 854-2774 to reschedule or at the Lab (408) 924-3056 on testing day.

PLEASE READ THE FOLLOWING INFORMATION CAREFULLY. It contains instructions which MUST be followed prior to reporting for testing.

1. Refrain from eating, smoking, or drinking caffeinated or carbonated beverages for at least 4 hours prior to testing.

2. Refrain from any unusual exercise at least 24 hours prior to testing day.

3. No exercise during the 2 hours prior to testing.

4. Wear comfortable exercise clothes (jog bra, short sleeved T-shirt or tank top, shorts and rubber soled exercise shoes (eg., running shoes) NO LEOTARDS OR BODY SUITS.

5. Do not wear lipstick (it is hard to remove from the mouthpiece).

6. Bring a water bottle and towel.

7. Please report for testing well rested.

8. Please arrive on time - we will make every effort to remain on schedule and complete your testing on time. Allow time for parking and walking to classroom (approximately 10 minutes).

9. Testing procedures will take approximately 1 hour.

Thanks for your interest and participation. If you have any questions, contact Barbara Love at (415) 854-2774.

Test date:

Time: 
APPENDIX E

\section{RATING OF PERCEIVED EXERTION (RPE) INSTRUCTIONS}

During the exercise test we want you to pay close attention to how hard you feel the work rate is. This feeling should be your total amount of exertion and fatigue, combining all sensations and feelings of physical stress, effort, and fatigue. Don't concern yourself with any one factor such as leg pain, shortness of breath or exercise intensity, but try to concentrate on your total, inner feeling of exertion. Don't underestimate or overestimate, just be as accurate as you can.

\section{RATING OF PERCEIVED EXERTION CATEGORY SCALE}

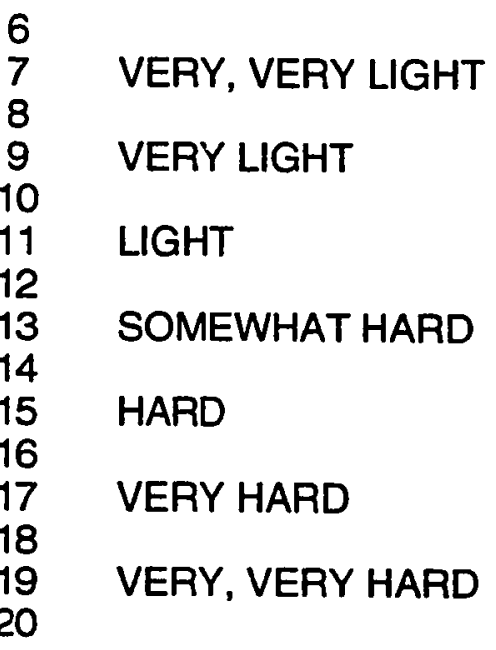

(ACSM GUIDELINES FOR EXERCISE TESTING AND PRESCRIPTION. 1991, pg. 71) 
APPENDIX F

Raw Data

\begin{tabular}{|c|c|c|c|}
\hline $113 \times 10 \% 150$ & 5 & FE & $\mathrm{ht}=\mathrm{cm}$ \\
\hline RPE $=$ NO & $6-10$ & & $w t=k g$ \\
\hline ST MIN 4 & 148 & 11 & age $=$ yrs \\
\hline ST MIN 5 & 144 & 13 & \\
\hline ST MIN 6 & 144 & 13 & \\
\hline & & & \\
\hline IRPE & & 13 & \\
\hline TM MIN 5 & 10 & 11 & \\
\hline TMMIN 6 & 140 & 12 & \\
\hline TM MIN 7 & 144 & 13 & \\
\hline TIM MIN 8 & 150 & 13 & \\
\hline TM MIN 9 & 146 & 14 & \\
\hline HPMAX & & & \\
\hline VOPMAX & 198 & & 110.110 .5 \\
\hline VULMAX & 42.7 & & $w t-70.6$ \\
\hline BPF\% & 28 & & |age-29 \\
\hline
\end{tabular}

\begin{tabular}{|c|c|c|c|}
\hline IB $/ \mathrm{NO}, \mathrm{CO}$ & $\mathbf{E}$ & $\mathrm{fez}$ & $\mathrm{ht}=\mathrm{cm}$ \\
\hline RPE $=$ YES & $11+$ & & $w t=k g$ \\
\hline ST MIN 4 & 93 & 9 & age=yrs \\
\hline ST MIN 5 & 95 & 9 & \\
\hline ST MIN 6 & 94 & 10 & \\
\hline IRPE & & 9 & \\
\hline & & & \\
\hline & & & \\
\hline TM MIN 2 & 65 & 9 & \\
\hline TM MIN 3 & 82 & 10 & \\
\hline TM MIN 4 & 84 & 11 & \\
\hline TM MIN 5 & 103 & 12 & \\
\hline HRMAX & 182 & & ht-167.2 \\
\hline VO2MAX & 50 & & $w t-61.3$ \\
\hline BPF\% & 25 & & lage-27 \\
\hline
\end{tabular}

\begin{tabular}{|c|c|c|c|}
\hline 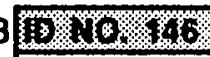 & $\mathrm{ne} / 2$ & ge & \\
\hline RPE $=$ NO & $11+$ & & \\
\hline ST MIN 4 & 127 & 7 & \\
\hline ST MIN 5 & 128 & 8 & \\
\hline ST MIN 6 & 133 & 9 & \\
\hline TRPE & & 8 & \\
\hline TM MIN 1 & 101 & 7 & \\
\hline TM MIN 2 & 107 & 7 & \\
\hline TM MIN 3 & 107 & $\overline{7}$ & \\
\hline TM MIN 4 & 110 & 8 & \\
\hline TM MIN 5 & 117 & 8 & \\
\hline TM MIN 6 & 122 & 9 & \\
\hline TM MIN 7 & 127 & 10 & \\
\hline TM MIN 8 & 138 & 11 & \\
\hline HRMAX & 193 & & ht -157.2 \\
\hline VO2MAX & 35 & & wt-59.3 \\
\hline$B P P \%$ & 25 & & age-32 \\
\hline
\end{tabular}

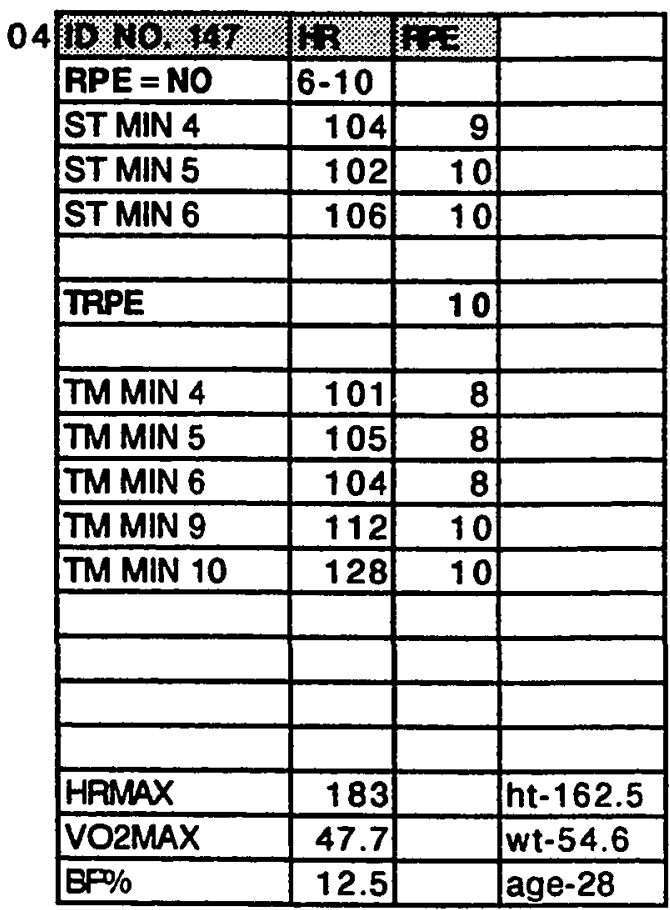




\begin{tabular}{|l|r|r|r|}
\hline 05 DMO TO7B & LE & FEZ & \\
\hline RPE $=$ YES & $0-5$ & & \\
\hline ST MIN 4 & 118 & 9 & \\
\hline ST MIN 5 & 115 & 10 & \\
\hline ST MIN 6 & 118 & 10 & \\
\hline & & & \\
\hline TRPE & & 10 & \\
\hline & & & \\
\hline TM MIN 4 & 117 & 7 & \\
\hline TM MIN 5 & 109 & 7 & \\
\hline TM MIN 6 & 123 & 8 & \\
\hline TM MIN 7 & 133 & 9 & \\
\hline TM MIN 8 & 131 & 9 & \\
\hline TM MIN 9 & 133 & 10 & \\
\hline TM MIN 10 & 135 & 10 & \\
\hline & & & \\
\hline HPMAX & 188 & & ht $=159.4$ \\
\hline VO2MAX & 46.2 & & wt-62.1 \\
\hline BF\% & 21.5 & & age-29 \\
\hline
\end{tabular}

\begin{tabular}{|c|c|c|c|}
\hline WDO MA & $\mathbf{F}$ & feE & \\
\hline RPE $=$ NO & $11+$ & & \\
\hline ST MIN 4 & 148 & 12 & \\
\hline ST MIN 5 & 156 & 12 & \\
\hline ST MIN 6 & 152 & 11 & \\
\hline TRPE & & 12 & \\
\hline & & & \\
\hline TMMIN 6 & 142 & 12 & \\
\hline TMMIN 7 & 150 & 12 & \\
\hline TM MIN 8 & 156 & 12 & \\
\hline TM MIN 9 & 156 & 13 & \\
\hline & & & \\
\hline & & & \\
\hline & & & \\
\hline HRMAX & 200 & & ht -157.0 \\
\hline VO2MAX & 44.8 & & $w t-52.0$ \\
\hline BPF\% & 22.7 & & age-29 \\
\hline
\end{tabular}

\begin{tabular}{|c|c|c|c|}
\hline $07 B \times 180,138$ & m & $\mathbf{L} \mathbf{3}$ & \\
\hline RPE = YES & $0-5$ & & \\
\hline ST MIN 4 & 104 & 9 & \\
\hline ST MIN 5 & 111 & $\overline{9}$ & \\
\hline ST MIN 6 & 114 & 10 & \\
\hline TRPE & & 9 & \\
\hline & & & \\
\hline TM MIN 4 & 103 & 9 & \\
\hline TM MIN 5 & 100 & 10 & \\
\hline TM MIN 6 & 112 & 10 & \\
\hline TM MIN 7 & 117 & 10 & \\
\hline TM MIN 8 & 122 & 11 & \\
\hline & & & \\
\hline & & & \\
\hline & & & \\
\hline & & & \\
\hline & & & \\
\hline & & & \\
\hline HPMAX & 185 & & $h t=154.5$ \\
\hline VO2MAX & 51.1 & & wt-52.5 \\
\hline $\mathrm{BP} \%$ & 23 & & age-25 \\
\hline
\end{tabular}

\begin{tabular}{|c|c|c|c|}
\hline $10 / 10<343$ & $h n$ & $F=$ & \\
\hline RPE = YES & $6-10$ & & \\
\hline STMIN 4 & 102 & 10 & \\
\hline ST MIN 5 & 109 & 11 & \\
\hline ST MIN 6 & 118 & 11 & \\
\hline TRPE & & 11 & \\
\hline & & & \\
\hline TM MIN 1 & 107 & 9 & \\
\hline TM MIN 2 & 97 & 10 & \\
\hline TM MIN 3 & 106 & 10 & \\
\hline TM MIN 4 & 113 & 10 & \\
\hline TM MIN 5 & 111 & 10 & \\
\hline TM MIN 6 & 111 & 11 & \\
\hline TM MIN 7 & 111 & 11 & \\
\hline TM MIN 8 & 118 & 11 & \\
\hline TM MIN 9 & 128 & 11 & \\
\hline TM MIN 10 & 122 & 11 & \\
\hline HRMAX & 193 & & ht-158.4 \\
\hline VORMAX & 47.4 & & $w t-55.8$ \\
\hline $\mathrm{BP} \%$ & 20.5 & & age-34 \\
\hline
\end{tabular}




\begin{tabular}{|c|c|c|c|}
\hline W1910 189 & $\mathbf{H}$ & FE: & \\
\hline RPE $=$ NO & $11+$ & & \\
\hline ST MIN 4 & 162 & 12 & \\
\hline ST MIN 5 & 156 & 12 & \\
\hline ST MIN 6 & 160 & 13 & \\
\hline TRPE & & 12 & \\
\hline & & & \\
\hline TM MIN 4 & 138 & 12 & \\
\hline TM MIN 5 & 142 & 13 & \\
\hline TM MIN 6 & 158 & 14 & \\
\hline TM MIN 7 & 173 & 15 & \\
\hline & & & \\
\hline HPIMAX & 203 & & ht-174.3 \\
\hline VO2MAX & 32.4 & & $w t-77.5$ \\
\hline$B F \%$ & 25 & & age-34 \\
\hline
\end{tabular}

\begin{tabular}{|c|c|c|c|}
\hline DONO $/ 148$ & 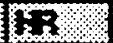 & $\overline{F E}$ & \\
\hline RPE $=$ NO & $111+$ & & \\
\hline ST MIN 4 & 140 & 12 & \\
\hline ST MIN 5 & 142 & 13 & \\
\hline ST MIN 6 & 146 & 14 & \\
\hline TRPE & & 13 & \\
\hline TM MIN 4 & 127 & 12 & \\
\hline TM MIN 5 & 131 & 12 & \\
\hline TM MIN 6 & 135 & 12 & \\
\hline TM MIN 7 & 140 & 13 & \\
\hline TM MIN 8 & 148 & 14 & \\
\hline TM MIN 9 & 152 & 15 & \\
\hline HRMAX & 190 & & ht-152.7 \\
\hline VO2MAX & 33.4 & & $w t-61.6$ \\
\hline $\mathrm{BP} \%$ & 29.5 & & age-37 \\
\hline
\end{tabular}

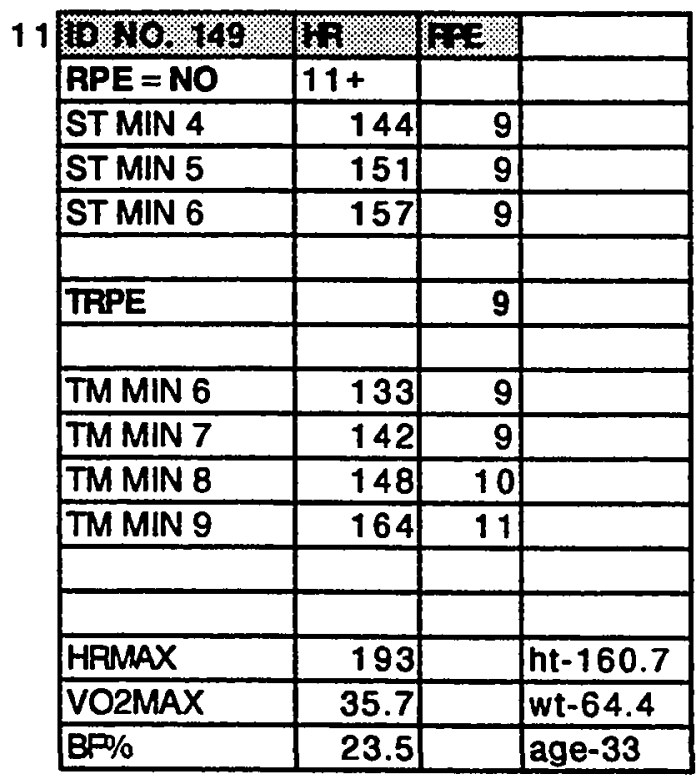

\begin{tabular}{|c|c|c|c|}
\hline MOTS 15 & $E x$ & Fis & \\
\hline RPE $=$ NO & $6-10$ & & \\
\hline ST MIN 4 & 105 & 9 & \\
\hline ST MIN 5 & 103 & 9 & \\
\hline ST MIN 6 & 106 & 9 & \\
\hline TRPE & & 9 & \\
\hline TM MIN 5 & 92 & 9 & \\
\hline TM MIN 6 & 99 & 9 & \\
\hline TM MIN 7 & 100 & 9 & \\
\hline TM MIN 8 & 103 & 10 & \\
\hline TM MIN 9 & 112 & 12 & \\
\hline HPMAX & 185 & & ht- 161.0 \\
\hline VO2MAX & 53.7 & & $w t-56.2$ \\
\hline BP\% & 17 & & age-29 \\
\hline
\end{tabular}




\begin{tabular}{|c|c|c|c|}
\hline DDNO $/ 42$ & $\mathbf{T R}$ & FPE & \\
\hline RPE $=$ YES & $11+$ & & \\
\hline ST MIN 4 & 158 & 9 & \\
\hline ST MIN 5 & 162 & $\overline{9}$ & \\
\hline ST MIN 6 & 162 & 9 & \\
\hline TRPE & & 9 & \\
\hline TM MIN 5 & 146 & 0 & \\
\hline TM MIN 6 & 154 & 10 & \\
\hline TM MIN 7 & 167 & 12 & \\
\hline HPIAX & 193 & & het 1767 \\
\hline VO2MAX & 28.8 & & $w t-108.6$ \\
\hline BF\% & 28 & & age-27 \\
\hline
\end{tabular}

\begin{tabular}{|c|c|c|c|}
\hline Do 10, 157 & $\mathbf{F B}$ & $\overline{F P E}$ & \\
\hline RPE $=$ NO & $11+$ & & \\
\hline ST MIN 4 & 127 & 12 & \\
\hline ST MIN 5 & 130 & 11 & \\
\hline ST MIN 6 & 133 & $\overline{11}$ & \\
\hline TRPE & & 11 & \\
\hline TMM MIN 9 & 132 & 11 & \\
\hline TM MIN 10 & 133 & 12 & \\
\hline TM MIN 11 & 138 & 12 & \\
\hline HFIMAX & 184 & & ht-168.7 \\
\hline VO2MAX & 39.2 & & $w t-66.4$ \\
\hline BP\% & 25.5 & & age-23 \\
\hline
\end{tabular}

\begin{tabular}{|c|c|c|c|}
\hline 510,16 S 53 & (3). & $6 \mathbf{E}$ & \\
\hline RPE = NO & $11+$ & & \\
\hline ST MIN 4 & 115 & 10 & \\
\hline ST MIN 5 & 117 & 12 & \\
\hline ST MIN 6 & 118 & 12 & \\
\hline TRPE & & 12 & \\
\hline TM MIN 4 & 111 & 11 & \\
\hline TM MIN 5 & 112 & 11 & \\
\hline TM MIN 6 & 117 & 12 & \\
\hline TM MIN 7 & 120 & 13 & \\
\hline HRMAX & 180 & & ht-159.7 \\
\hline VO2MAX & 50.8 & & $w t \cdot 48.8$ \\
\hline $\mathrm{BP} \%$ & 22 & & age-29 \\
\hline
\end{tabular}

\begin{tabular}{|c|c|c|c|}
\hline Do 10.66 & K8: & PPE & \\
\hline RPE $=$ YES & $11+$ & & \\
\hline ST MIN 4 & 112 & 10 & \\
\hline ST MIN 5 & 113 & 10 & \\
\hline ST MIN 6 & 115 & 10 & \\
\hline TRPE & & 10 & \\
\hline TM MIN 5 & 100 & 10 & \\
\hline TM MIN 6 & 103 & 10 & \\
\hline TM MIN 7 & 106 & 11 & \\
\hline TM MIN 8 & 115 & 12 & \\
\hline HPMAX & 173 & & $h+1610$ \\
\hline VO2MAX & 44.4 & & $\frac{164.9}{w t-164.9}$ \\
\hline $\mathrm{BF} \%$ & 19.5 & & age-33 \\
\hline
\end{tabular}


62

\begin{tabular}{|c|c|c|c|}
\hline 13) & $\mathbf{H R}$ & RPE & \\
\hline RPE = YES & $11+$ & & \\
\hline ST MIN 4 & 127 & 7 & \\
\hline ST MIN 5 & 127 & 8 & \\
\hline ST PAIN 6 & 131 & 8 & \\
\hline TRPE & & 8 & \\
\hline & & & \\
\hline TM MIN 5 & 103 & 8 & \\
\hline TM MIN 6 & 106 & 8 & \\
\hline TM MIN 7 & 112 & 9 & \\
\hline TM MIN 8 & 127 & 10 & \\
\hline TM MIN 9 & 140 & 11 & \\
\hline HPMAX & 187 & & $h t-160.8$ \\
\hline VO2MAX & 47.3 & & $w t-61.6$ \\
\hline $\mathrm{BF} \%$ & 22 & & age-23 \\
\hline
\end{tabular}

\begin{tabular}{|l|r|r|l|}
\hline 18 & DW. \\
\hline RPE $=$ YES & $11+$ & & \\
\hline ST MIN 4 & 120 & 7 & \\
\hline ST MIN 5 & 123 & 7 & \\
\hline ST MIN 6 & 120 & 8 & \\
\hline & & & \\
\hline IRPE & & 7 & \\
\hline & & & \\
\hline TM MIN 1 & 96 & 7 & \\
\hline TM MIN 2 & 103 & 8 & \\
\hline TM MIN 3 & 111 & 9 & \\
\hline TM MIN 4 & 125 & 12 & \\
\hline TM MIN 5 & 131 & 13 & \\
\hline & & & \\
\hline HRMAX & 198 & & ht-173.5 \\
\hline VO2MAX & 50.6 & & wt-74.2 \\
\hline BPF & 25.5 & & age-26 \\
\hline
\end{tabular}

\begin{tabular}{|c|c|c|c|}
\hline S1OK 151 & 12 & $\mathbf{E} \mathbf{E}$ & \\
\hline RPE $=$ NO & 6.10 & & \\
\hline ST MIN 4 & 113 & 7 & \\
\hline ST MIN 5 & 111 & $\overline{7}$ & \\
\hline ST MIN 6 & 109 & 8 & \\
\hline TRPE & & 7 & \\
\hline & & & \\
\hline TM MIN 1 & 90 & 7 & \\
\hline TM MIN 2 & 95 & 7 & \\
\hline TM MIN 3 & 94 & 7 & \\
\hline TM MIN 4 & 95 & 7 & \\
\hline TIM MIN 5 & 98 & 7 & \\
\hline TM MIN 6 & 103 & $\overline{7}$ & \\
\hline TM MIN 7 & 106 & 8 & \\
\hline TIM MIN 8 & 109 & 9 & \\
\hline HAMAX & 183 & & ht-159.1 \\
\hline VO2MAX & 48.6 & & $w t-60.9$ \\
\hline BF\% & 19.5 & & age-26 \\
\hline
\end{tabular}

\begin{tabular}{|c|c|c|c|}
\hline 01010.1028 & $\mathbf{E t}$ & 10 & \\
\hline RPE $=$ YES & $11+$ & & \\
\hline ST MIN 4 & 132 & 9 & \\
\hline ST MIN 5 & 135 & 9 & \\
\hline ST MIN 6 & 133 & 10 & \\
\hline TRPE & 9 & & \\
\hline TM MIN 4 & 131 & 9 & \\
\hline TM MIN 5 & 129 & 10 & \\
\hline TM MIN 6 & 133 & 11 & \\
\hline & & & \\
\hline & & & \\
\hline & & & \\
\hline & & & \\
\hline & & & \\
\hline HFMAX & 200 & & ht-164.6 \\
\hline VO2MAX & 50.2 & & $w t-54.8$ \\
\hline $\mathrm{BP} \%$ & 18.5 & & age-25 \\
\hline
\end{tabular}




\begin{tabular}{l|r|r|r|l|}
\hline 21 & TMO. 198 & G & FPE & \\
\hline RPE $=$ NO & $11+$ & & \\
\hline ST MIN 4 & 118 & 11 & \\
\hline ST MIN 5 & 120 & 11 & \\
\hline ST MIN 6 & 115 & 12 & \\
\hline & & & \\
\hline TRPE & & 11 & \\
\hline & & & \\
\hline TM MIN 1 & 112 & 11 & \\
\hline TM MIN 2 & 107 & 12 & \\
\hline TM MIN 3 & 109 & 12 & \\
\hline TM MIN 4 & 123 & 13 & \\
\hline & & & \\
\hline HRMAX & 188 & & ht-166.4 \\
\hline VO2MAX & 42 & & wt-58.4 \\
\hline BPF & 23 & & age-30 \\
\hline
\end{tabular}

\begin{tabular}{|c|c|c|c|}
\hline $10 \%$ TO 152 & $\mathrm{HB}$ & PPE & \\
\hline RPE $=$ NO & $11+$ & & \\
\hline ST MIN 4 & 117 & 9 & \\
\hline ST MIN 5 & 122 & 9 & \\
\hline ST MIN 6 & 118 & 10 & \\
\hline TRPE & & 9 & \\
\hline TM MIN 3 & 96 & 9 & \\
\hline TM MIN 4 & 106 & 11 & \\
\hline TMMIN 5 & 118 & 12 & \\
\hline TM MIN 6 & 130 & 13 & \\
\hline HRMAX & 190 & & ht-174.1 \\
\hline VO2MAX & 40 & & $w t-60.3$ \\
\hline $\mathrm{BP} \%$ & 17.8 & & age-30 \\
\hline
\end{tabular}

\begin{tabular}{|c|c|c|c|}
\hline mNo 19 & s: & $\mathbf{P O E}$ & \\
\hline RPE $=$ NO & $11+$ & & \\
\hline ST MIN 4 & 112 & 8 & \\
\hline ST MIN 5 & 108 & 8 & \\
\hline ST MIN 6 & 107 & 9 & \\
\hline TRPE & & 8 & \\
\hline & & & \\
\hline TM MIN 3 & 96 & 8 & \\
\hline TM MIN 4 & 96 & 8 & \\
\hline TM MIN 5 & 100 & 9 & \\
\hline TM MIN 6 & 112 & 9 & \\
\hline TM MIN 7 & 123 & 11 & \\
\hline HRMAX & 193 & & ht-157.3 \\
\hline VO2MAX & 49 & & $w t-49.8$ \\
\hline $\mathrm{BP} \%$ & 20.5 & & age-22 \\
\hline
\end{tabular}

\begin{tabular}{|c|c|c|c|}
\hline$4 \longdiv { 1 0 1 0 / 5 9 }$ & $\mathrm{BP}$ & PPE & \\
\hline RPE $=$ NO & $0-5$ & & \\
\hline ST MIN 4 & 112 & 11 & \\
\hline STMIN 5 & 117 & 11 & \\
\hline ST MIN 6 & 114 & 12 & \\
\hline TRPE & & 11 & \\
\hline TM MIN 7 & 110 & 11 & \\
\hline TM MIN 8 & 109 & 11 & \\
\hline TMMIN 9 & 114 & 11 & \\
\hline TM MIN 10 & 109 & 11 & \\
\hline TM MIN 11 & 122 & 12 & \\
\hline HPMAX & 190 & & ht-156.6 \\
\hline VO2MAX & 46.7 & & $w t-46.7$ \\
\hline$B P \%$ & 16.5 & & age-26 \\
\hline
\end{tabular}


64

\begin{tabular}{|c|c|c|c|}
\hline $50 \% 10,155$ & $\mathrm{HA}:$ & REE & \\
\hline RPE $=$ NO & $6-10$ & & \\
\hline ST MIN 4 & 120 & 8 & \\
\hline ST MIN 5 & 118 & 9 & \\
\hline ST MIN 6 & 122 & 11 & \\
\hline TRPE & & 0 & \\
\hline TM MIN 4 & 109 & 9 & \\
\hline TM MIN 5 & 118 & 10 & \\
\hline TM MIN 6 & 117 & 10 & \\
\hline TM MIN 7 & 117 & 11 & \\
\hline TM MIN 8 & 124 & 11 & \\
\hline TM MIN 9 & 140 & 11 & \\
\hline HPIMAX & 188 & & ht-164.8 \\
\hline VO2MAX & 39.7 & & wt-56.5 \\
\hline $\mathrm{BP} \%$ & 20 & & age-22 \\
\hline
\end{tabular}

\begin{tabular}{|l|r|r|l|}
\hline 26 D NO. 162 & FR & PPE & \\
\hline RPE = NO & $11+$ & & \\
\hline ST MIN 4 & 163 & 11 & \\
\hline ST MIN 5 & 169 & 12 & \\
\hline ST MIN 6 & 167 & 12 & \\
\hline & & & \\
\hline TRPE & & 12 & \\
\hline & & & \\
\hline TM MIN 5 & 148 & 12 & \\
\hline TM MIN 6 & 150 & 12 & \\
\hline TM MIN 7 & 158 & 13 & \\
\hline TM MIN 8 & 171 & 13 & \\
\hline & & & \\
\hline & & & \\
\hline & & & \\
\hline HPMAX & 209 & & ht-164.0 \\
\hline VO2MAX & 32.8 & & wt-77.6 \\
\hline BF\% & 26 & & age-26 \\
\hline
\end{tabular}

\begin{tabular}{|c|c|c|c|}
\hline $2713 \times 10.963$ & $\sqrt{8-2}$ & WEI & \\
\hline RPE = YES & $11+$ & & \\
\hline ST MIN 4 & 127 & 8 & \\
\hline ST MIN 5 & 132 & 7 & \\
\hline ST MIN 6 & 127 & 9 & \\
\hline TRPE & & 7 & \\
\hline & & & \\
\hline TM MIN 1 & 112 & 7 & \\
\hline TM MIN 2 & 109 & 7 & \\
\hline TM MIN 3 & 112 & 8 & \\
\hline TM MIN 4 & 108 & 10 & \\
\hline TM MIN 5 & 117 & 1.2 & \\
\hline TM MIN 6 & 133 & 13 & \\
\hline TM MIN 7 & 152 & 15 & \\
\hline HAMAX & 190 & & ht-164.8 \\
\hline VO2MAX & 41.9 & & $w t-64.2$ \\
\hline$B F \%$ & 24.5 & & $\longdiv { \operatorname { a g e - 3 4 } }$ \\
\hline
\end{tabular}

\begin{tabular}{|c|c|c|c|}
\hline MYO /G4 & $m=3$ & SPE & \\
\hline RPE = NO & $11+$ & & \\
\hline ST MIN 4 & 136 & 9 & \\
\hline ST MIN 5 & 135 & 10 & \\
\hline ST MIN 6 & 138 & 10 & \\
\hline TRPE & & 10 & \\
\hline TM MIN 7 & 130 & 9 & \\
\hline TM MIN 8 & 136 & 10 & \\
\hline TIM MIN 9 & 142 & 10 & \\
\hline TIM MIN 10 & 144 & 11 & \\
\hline & & & \\
\hline & & & \\
\hline & & & \\
\hline HRMAX & 195 & & ht-170.8 \\
\hline VO2MAX & 39.5 & & wt-63.6 \\
\hline BP\% & 24.5 & & age-27 \\
\hline
\end{tabular}




\begin{tabular}{|l|r|r|r|}
\hline 29 DIO. 65 & IR & $\mathrm{FPE}$ & \\
\hline RPE = NO & $0-5$ & & \\
\hline ST MIN 4 & 147 & 11 & \\
\hline ST MIN 5 & 140 & 13 & \\
\hline ST MIN 6 & 152 & 15 & \\
\hline & & & \\
\hline TRPE & & 13 & \\
\hline & & & \\
\hline TM MIN 5 & 144 & 13 & \\
\hline TM MIN 6 & 150 & 15 & \\
\hline TM MIN 7 & 162 & 17 & \\
\hline & & & \\
\hline & & & \\
\hline & & & \\
\hline & & & \\
\hline HRMAX & 185 & & ht-165.4 \\
\hline VO2MAX & 29.1 & & wt-67.1 \\
\hline BPF & 30 & & age-36 \\
\hline
\end{tabular}

\begin{tabular}{|c|c|c|c|}
\hline TOMO 158 & $\mathrm{ER}$ & $\overline{\mathrm{APE}}$ & \\
\hline RPE $=$ NO & $11+$ & & \\
\hline ST MIN 4 & 136 & 11 & \\
\hline ST MIN 5 & 136 & 11 & \\
\hline ST MIN 6 & 138 & 12 & \\
\hline TRPE & & 11 & \\
\hline & & & \\
\hline TM MIN 1 & 112 & 11 & \\
\hline TM MIN 2 & 122 & 11 & \\
\hline TM MIN 3 & 118 & 12 & \\
\hline TM MIN 4 & 127 & 12 & \\
\hline TM MIN 5 & 140 & 14 & \\
\hline TM MIN 6 & 147 & 14 & \\
\hline HAMAX & 197 & & ht-167.9 \\
\hline VO2MAX & 42.7 & & $w t-60.0$ \\
\hline $\mathrm{BP} \%$ & 18.5 & & age-22 \\
\hline
\end{tabular}

\begin{tabular}{|c|c|c|c|}
\hline 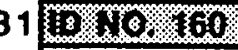 & 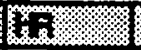 & DPE: & \\
\hline RPE $=$ NO & 0.5 & & \\
\hline ST MIN 4 & 113 & 11 & \\
\hline ST MIN 5 & 122 & 12 & \\
\hline ST MIN 6 & 125 & 12 & \\
\hline TRPE & & 12 & \\
\hline & & & \\
\hline TM MIN 5 & 117 & 12 & \\
\hline TM MIN 6 & 118 & $\overline{12}$ & \\
\hline TM MIN 7 & 122 & 13 & \\
\hline TM MIN 8 & 138 & 13 & \\
\hline & & & \\
\hline & & & \\
\hline & & & \\
\hline & & & \\
\hline HPMAX & 190 & & $h t-1582$ \\
\hline VO2MAX & 50 & & wt-49.0 \\
\hline BF\% & 17 & & age-21 \\
\hline
\end{tabular}

\begin{tabular}{|c|c|c|c|}
\hline 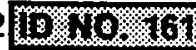 & 18 & s:s: & \\
\hline RPE $=$ NO & $11+$ & & \\
\hline ST MIN 4 & 129 & 11 & \\
\hline ST MIN 5 & 136 & 11 & \\
\hline ST MIN 6 & 120 & 11 & \\
\hline TRPE & & 11 & \\
\hline & & & \\
\hline TM MIN 6 & 120 & 9 & \\
\hline TM MIN 7 & 119 & 9 & \\
\hline TM MIN 8 & 121 & 9 & \\
\hline TM MIN 9 & 130 & 9 & \\
\hline TM MIN 10 & 135 & 9 & \\
\hline TM MIN 11 & 135 & 11 & \\
\hline TM MIN 12 & 136 & 11 & \\
\hline TM MIN 13 & 136 & 11 & \\
\hline TM MIN 14 & 144 & 11 & \\
\hline HAMAX & 197 & & ht -175.0 \\
\hline VO2MAX & 48.6 & & $w t-69.5$ \\
\hline $\mathrm{BP} \%$ & 21 & & age-27 \\
\hline
\end{tabular}




\begin{tabular}{|l|r|r|l|}
\hline 33 PMO 154 & YR & FPE & \\
\hline RPE = YES & $11+$ & & \\
\hline ST MIN 4 & 93 & 8 & \\
\hline ST MIN 5 & 95 & 9 & \\
\hline ST MIN 6 & 93 & 9 & \\
\hline & & & \\
\hline JRPE & & 9 & \\
\hline & & & \\
\hline TM MIN 1 & 84 & 9 & \\
\hline TM MIN 2 & 89 & 9 & \\
\hline TM MIN 3 & 92 & 10 & \\
\hline TM MIN 4 & 91 & 11 & \\
\hline TM MIN 5 & 100 & 11 & \\
\hline & & & \\
\hline HPMAX & 165 & & ht-161.3 \\
\hline VO2MAX & 61.4 & & wt-54.7 \\
\hline BP\% & 14 & & age-41 \\
\hline
\end{tabular}

\begin{tabular}{|c|c|c|c|}
\hline 10:10. 156 & $\mathbf{R B}$ & APE & \\
\hline RPE $=$ YES & $11+$ & & \\
\hline ST MIN 4 & 97 & 9 & \\
\hline ST MIN 5 & 100 & 9 & \\
\hline ST MIN 6 & 103 & 9 & \\
\hline JRPE & & 9 & \\
\hline TM MIN 4 & 88 & 9 & \\
\hline TM MIN 5 & 93 & 10 & \\
\hline TM MIN 6 & 99 & 12 & \\
\hline TM MIN 7 & 112 & 12 & \\
\hline & & & \\
\hline HRMAX & 185 & & ht-172.1 \\
\hline VO2MAX & 52.1 & & $w t-54.2$ \\
\hline$B P \%$ & 13 & & age-26 \\
\hline
\end{tabular}

\begin{tabular}{|c|c|c|c|}
\hline 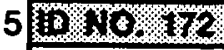 & 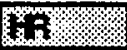 & DPE & \\
\hline RPE $=$ NO & $11+$ & & \\
\hline ST MIN 4 & 133 & 7 & \\
\hline STMIN 5 & 132 & 8 & \\
\hline ST MIN 6 & 135 & 9 & \\
\hline TRPE & & 8 & \\
\hline TM MIN 1 & 109 & 9 & \\
\hline TM MIN 2 & 109 & 9 & \\
\hline TM MIN 5 & 131 & 13 & \\
\hline TM MIN 6 & 150 & 13 & \\
\hline & & & \\
\hline & & & \\
\hline & & & \\
\hline & & & \\
\hline HPMAX & 200 & & \\
\hline VO2MAX & 45.1 & & $w t-52.0$ \\
\hline $\mathrm{BP} \%$ & 23 & & age-36 \\
\hline
\end{tabular}

\begin{tabular}{|c|c|c|c|}
\hline $610 \times 10 / 20$ & 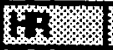 & 108 & \\
\hline RPE $=$ NO & 0.5 & & \\
\hline ST MIN 4 & 95 & 11 & \\
\hline STMIN 5 & 95 & 11 & \\
\hline ST MIN 6 & 99 & 12 & \\
\hline TRPE & & 11 & \\
\hline TM MIN 1 & 85 & 11 & \\
\hline TTM MIN 2 & 82 & 11 & \\
\hline TM MIN 3 & 80 & 11 & \\
\hline TM MIN 4 & 85 & 11 & \\
\hline TM MIN 5 & 88 & 11 & \\
\hline TM MIN 6 & 91 & 11 & \\
\hline TM MIN 7 & 96 & 12 & \\
\hline TM MIN 8 & 114 & 13 & \\
\hline HRMAX & 173 & & ht-165.8 \\
\hline VO2MAX & 44.1 & & $w t-65.0$ \\
\hline$B P \%$ & 24 & & age-37 \\
\hline
\end{tabular}




\begin{tabular}{|c|c|c|c|}
\hline 373010 SO & $\mathbf{f}$ & PRE & \\
\hline RPE $=$ NO & $11+$ & & \\
\hline ST MIN 4 & 136 & 11 & \\
\hline ST MIN 5 & 133 & 11 & \\
\hline ST MIN 6 & 142 & 11 & \\
\hline TRPE & & 11 & \\
\hline TM MIN 1 & 120 & 11 & \\
\hline TM MIN 2 & 118 & 10 & \\
\hline TM MIN 3 & 130 & 11 & \\
\hline TM MIN 4 & 131 & 12 & \\
\hline TM MIN 5 & 136 & 12 & \\
\hline TM MIN 6 & 140 & 13 & \\
\hline & & & \\
\hline HRMAX & 190 & & ht-169.0 \\
\hline VO2MAX & 52.7 & & $w t-62.3$ \\
\hline$B F \%$ & 19.5 & & age-28 \\
\hline
\end{tabular}

\begin{tabular}{|l|r|r|l|}
\hline 38 DMO. 167 & FR & FPE & \\
\hline RPE = NO & $11+$ & & \\
\hline ST MIN 4 & 123 & 11 & \\
\hline ST MIN 5 & 128 & 11 & \\
\hline ST MIN 6 & 131 & 11 & \\
\hline & & & \\
\hline IRPE & & 11 & \\
\hline & & & \\
\hline TM MIN 3 & 125 & 7 & \\
\hline TM MIN 4 & 138 & 8 & \\
\hline TM MIN 5 & 135 & 9 & \\
\hline TM MIN 6 & 149 & 11 & \\
\hline & & & \\
\hline & & & \\
\hline & & & \\
\hline HRMAX & 193 & & ht -170.0 \\
\hline VO2MAX & 41.4 & & wt-61.5 \\
\hline EPF\% & 18 & & age-28 \\
\hline
\end{tabular}

\begin{tabular}{|c|c|c|c|}
\hline 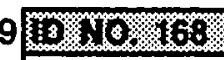 & 17 & Hes & \\
\hline RPE $=$ NO & $11+$ & & \\
\hline ST MIN 4 & 115 & 8 & \\
\hline ST MIN 5 & 114 & 8 & \\
\hline ST MIN 6 & 112 & 9 & \\
\hline TRPE & & 8 & \\
\hline & & & \\
\hline TM MIN 1 & 93 & 9 & \\
\hline TM MIN 2 & 104 & 9 & \\
\hline TM MIN 3 & 109 & 9 & \\
\hline TM MIN 4 & 106 & 9 & \\
\hline TM MIN 5 & 109 & 9 & \\
\hline TM MIN 6 & 104 & 9 & \\
\hline TM MIN 7 & 112 & 10 & \\
\hline TM MIN 8 & 123 & 11 & \\
\hline HRMAX & 183 & & $h t-171.0$ \\
\hline VO2MAX & 46.6 & & $w t-61.9$ \\
\hline$B P \%$ & 20.5 & & age-26 \\
\hline
\end{tabular}

\begin{tabular}{|c|c|c|c|}
\hline $010 / 10 \cdot 17 \%$ & 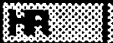 & $x=3$ & \\
\hline RPE $=$ YES & $6-10$ & & \\
\hline ST MIN 4 & 138 & 10 & \\
\hline ST MIN 5 & 131 & 10 & \\
\hline ST MIN 6 & 136 & 11 & \\
\hline TRPE & & 10 & \\
\hline TM MIN 2 & 123 & 10 & \\
\hline TM MIN 4 & 133 & 12 & \\
\hline TM MIN 5 & 144 & 13 & \\
\hline & & & \\
\hline & & & \\
\hline & & & \\
\hline & & & \\
\hline & & & \\
\hline HPMAX & 188 & & ht- 161.0 \\
\hline VO2MAX & 35.8 & & $w t-66.3$ \\
\hline BPD' & 27.5 & & age-31 \\
\hline
\end{tabular}




\begin{tabular}{|c|c|c|c|}
\hline 1 (5) 10.169 & $\mathbf{T A}$ & FEE & \\
\hline RPE $=$ YES & $11+$ & & \\
\hline ST MIN 4 & 96 & 12 & \\
\hline ST MIN 5 & 95 & 13 & \\
\hline ST MIN 6 & 96 & 13 & \\
\hline TRPE & & 13 & \\
\hline TMMIN 4 & 93 & 9 & \\
\hline TMMIN 5 & 97 & 12 & \\
\hline TM MIN 6 & 95 & 12 & \\
\hline TM MIN 7 & 106 & 13 & \\
\hline TM MIN 8 & 106 & 13 & \\
\hline TM MIN 9 & 111 & 13 & \\
\hline TM MIN 10 & 113 & 13 & \\
\hline HRMAX & 185 & & ht-166.9 \\
\hline VO2MAX & 56.8 & & $w t-50.2$ \\
\hline BP\% & 14 & & age-31 \\
\hline
\end{tabular}

\begin{tabular}{|l|r|r|l|}
\hline 42 MO. TS & FR & GPE & \\
\hline RPE = YES & $0-5$ & & \\
\hline ST MIN 4 & 127 & 12 & \\
\hline ST MIN 5 & 123 & 13 & \\
\hline ST MIN 6 & 130 & 13 & \\
\hline & & & \\
\hline TRPE & & 13 & \\
\hline & & & \\
\hline TM MIN 4 & 125 & 14 & \\
\hline TM MIN 5 & 129 & 14 & \\
\hline TM MIN 6 & 131 & 14 & \\
\hline TM MIN 7 & 140 & 14 & \\
\hline TM MIN 8 & 147 & 14 & \\
\hline & & & \\
\hline & & & \\
\hline & & & \\
\hline HRMAX & 180 & & ht-154.4 \\
\hline VO2MAX & 42.6 & & wt-67.6 \\
\hline BP\% & 26 & & age-28 \\
\hline
\end{tabular}


APPENDIX G

Data File

For thesis students: The following is a sample of the data file that was used in SPSS for the statistical analysis. Remember you are limited to 80 characters per line in SPSS.

01150112914814414411131313999999999999142140144150146 99999999999999999999999111213131499999919742.728 .0

02140022709309509409091009079065082084103999999999999 99999999999999908091011129999999999999918250.025 .0

03146123212712813307080908101107107110117122127138999 99999999999999999999908080899101099999918347.712 .5 
APPENDIX H

\section{Definition File}

For thesis students using a dependent $₫$ test for statistical analysis. The following is the definition file used in this study:

Data List File $=$ 'a:Thesis.dat'

/id 1-2 sub 4-6 q1 10 age 12-13 HRSTM4 15-17 HRSTM 5 19-21 HRSTM6 23-25

RPESTM4 27-28 RPESTM5 30-31 RPESTM6 33-34

TRPE 36-37 HRTMM1 39-41 HRTMM2 43-45 HRTMM3 47-49

HRTMM4 51-53 HRTMM5 55-57 HRTMM6 59-61 HRTM7 63-65 HRTMM8 67-69

HRTMM9 71-73 HRTMM10 75-77

/HRTMM11 1-3 HRTMM12 5-7 HRTM 13 9-11 HRTMM14 13-15

RPETMM1 17-18 RPETMM2 20-21 RPETMM3 23-24 RPETMM4 26-27

RPETMM5 29-30 RPETMM6 32-33 RPETMM7 35-36 RPETMM8 38-39

RPETMM9 41-42 RPETMM10 44-45 RPETMM11 47-48 RPETMM12 50-51

RPETMM13 53-54 RPETMM14 56-57 HRMAX 59-61 VO2MAX 63-66 BFP 68-71

S173-75 S2 77-79.

VAR LAB ID 'ID NUMBER'

Q1 'RPE USE'

Q2 'STEP CLASS'

S1 'STEP HRs'

S2 'TM HRs'

VAL LAB Q1 0 'YES' 1 'NO'

/Q2 0 '0-5' 1 '610' 2 '11+'.

missing value $\mathrm{q} 1$ to $\mathrm{q} 2(9)$

lage RPESTM4 TO TRPE RPETMM1 RPETMM14 (99)

/HRSTM4 TO HRSTM6 HRTMM1 HRTMM14 HRMAX (999)

NO2MAX BFP (9999).

list var $=q 1$ to $S 2$ cases $=2$.

freq $\operatorname{var}=q 1$ to $S 2$.

save file $=$ 'thesis.stm'. 


\section{APPENDIX I}

\section{Program File}

For thesis students using a dependent $₫$ test for statistical analysis. The following is the program file used for this research study.

get file $=$ 'thesis.stm'.

"First, here are descriptive statistics for age, TRPE, VO2max, BFP. descriptives var = age TRPE VO2max BFP.

*look at descriptives on q1 and q2 categorical.

freq $v a r=q 1 \mathrm{q} 2$.

*to examine the question - are there differences in HR on the bench step vs a TM at target RPE - a dependent t-test will be done if I meet the assumptions for a ttest.

freq var $=S 1$

/format=notable /hist

/stats = stdev.

freq var $=$ S2

/format=notable /hist

/stats $=$ stdev.

"From a liberal point of view I feel assumptions were met to do a parametric test. t-tests pairs $=\mathrm{S} 1 \mathrm{~S} 2$. 